\title{
Using Carbon and Oxygen Isotopes to Monitor Water-Rock Interaction Under Simulated Geothermal Conditions
}

\author{
Stephen J. Henry
}

Follow this and additional works at: https://researchrepository.wvu.edu/etd

\section{Recommended Citation}

Henry, Stephen J., "Using Carbon and Oxygen Isotopes to Monitor Water-Rock Interaction Under Simulated Geothermal Conditions" (2017). Graduate Theses, Dissertations, and Problem Reports. 5794. https://researchrepository.wvu.edu/etd/5794

This Thesis is protected by copyright and/or related rights. It has been brought to you by the The Research Repository @ WVU with permission from the rights-holder(s). You are free to use this Thesis in any way that is permitted by the copyright and related rights legislation that applies to your use. For other uses you must obtain permission from the rights-holder(s) directly, unless additional rights are indicated by a Creative Commons license in the record and/ or on the work itself. This Thesis has been accepted for inclusion in WVU Graduate Theses, Dissertations, and Problem Reports collection by an authorized administrator of The Research Repository @ WVU. For more information, please contact researchrepository@mail.wvu.edu. 


\title{
Using Carbon and Oxygen Isotopes to Monitor Water-Rock Interaction Under Simulated Geothermal Conditions
}

\author{
Stephen J. Henry \\ Thesis submitted \\ to the Eberly College of Arts and Sciences \\ at West Virginia University
}

in partial fulfillment of the requirements for the degree of

Master of Science in

Geology

\author{
Shikha Sharma, Ph.D., Chair \\ Alexandra Hakala, Ph.D. \\ Timothy Carr, Ph.D. \\ Department of Geology \& Geography
}

Morgantown, West Virginia

2017

Keywords: Carbon, Oxygen, Isotopes, Water-Rock Interaction, Enhanced Geothermal Systems Copyright 2017 Stephen Henry 


\section{Abstract \\ USING CARBON AND OXYGEN ISOTOPES TO MONITOR WATER-ROCK INTERACTION UNDER SIMULATED GEOTHERMAL CONDITIONS}

\section{Stephen J. Henry}

Engineered or Enhanced Geothermal Systems (EGS) have to potential to unlock vast hightemperature energy resources that lack the natural permeability and fluid flow required for power generation. In order to ensure sustained fracture connectivity in EGS, water-rock interactions must be understood in high temperature and pressure systems. Using cores from Brady's Field Well $\mathrm{BCH}-03$, investigations were conducted to test the feasibility of using carbon and oxygen isotopes to monitor water-rock interactions under simulated geothermal conditions. Reactions were examined in a series of high-temperature pressure vessels and a high-temperature flowthrough system in which a calcium bicarbonate solution was exposed to meta-volcanic rocks from up to three target depths (1358, 1396, and $1459 \mathrm{~m})$. Experiments were conducted for 14-20 days at $90-144^{\circ} \mathrm{C}$ and $103-120$ bar. A comprehensive characterization of the cores was conducted prior to experiments to assess the isotopic compositions of the rock samples. Water samples were collected before and after each experiment for isotopic and geochemical analyses. Samples were collected more frequently in the high-temperature flow-through system. Throughout the experiments, the isotopic results revealed significant enrichments of $\delta^{13} \mathrm{C}_{\text {DIC }}$ in the solution while $\delta^{18} \mathrm{O}_{\mathrm{H} 2 \mathrm{O}}$ remained unaffected by water-rock interaction. Geochemical data exhibited a decline in calcium and alkalinity and an increase in sodium and potassium concentrations in solution. The results indicate that the calcium bicarbonate solution, undersaturated with calcite, drove initial calcite dissolution in the rock. As the temperature increased and the solubility of $\mathrm{CO}_{2}$ declined, the solution became oversaturated with calcite, leading to $\mathrm{CO}_{2}$ degassing and subsequently calcite precipitation. The lack of measurable $\delta^{18} \mathrm{O}$ shifts can be attributed to the abundance of oxygen in the solution that constrained the impact of water-rock interaction. The $\delta^{13} \mathrm{C}_{\text {DIC }}$ results indicate the presence of significant calcite dissolution in all experiments with carbon isotope mixing models from the static reactor experiments suggesting a 37.8 to $54.6 \%$ contribution of $\delta^{13} \mathrm{C}$ from the rock to the post-reaction fluid. Although early-stage calcite dissolution may have temporarily increased the calcium and alkalinity concentrations in solution, the effects of $\mathrm{CO}_{2}$ degassing and subsequent calcite precipitation dominate the geochemical results. The geochemical data also suggests the presence of silicate mineral reactions not observed in the isotopic results. 


\section{Acknowledgements}

I would like to thank my graduate thesis advisor, Dr. Shikha Sharma, whose patience, support and consultation throughout the research process made this project possible. I would also like to thank the members of my thesis committee, Dr. Alexandra Hakala, and Dr. Timothy Carr, who provided critical expertise and feedback throughout this project. Furthermore, I would like to acknowledge the Department of Energy and the National Energy Technology Laboratory for providing project funding for this research under the DE-FOA-0000552 Funding Opportunity Announcement. For assistance throughout the months of installation, experimentation, and operation of the experimental systems, I would like to extend my gratitude to Dustin Crandall of the National Energy Technology Laboratory and Karl Jarvis of the URS Corporation. I would also like to thank James Fazio and Jeff Martin of the Oak Ridge Institute for Science and Education for their assistance with the static reactor experiments at the Pittsburgh National Energy Technology Laboratory. Finally, I would like to extend appreciation to Ajay Warrier and Vikas Agrawal of West Virginia University for assistance with laboratory experiments and sample analysis

Stephen J. Henry

West Virginia University

January, 2017 


\section{Table of Contents}

Abstract $\quad$ ii

Acknowledgements

Table of Contents

List of Figures $\quad$ V

List of Tables

1.0 - Introduction 1

1.1 - Site Description \& Project History $\quad 7$

$\begin{array}{ll}1.2 \text { - Format of Thesis } & 10\end{array}$

2.0 - Using Carbon and Oxygen Isotopes to Monitor Water-Rock Interaction Under Simulated Geothermal Conditions in Static Pressure Vessel Systems 11

2.1 - Introduction 12

Site Description and Experimental Setup

2.2 - Methods 16

2.3 - Results $\quad 18$

2.3 - Discussion 21

Carbon and Oxygen Isotopes $\quad 22$

Two Endmember Mixing Model 24

Geochemical Data 26

2.5 Conclusions 29

2.6 Acknowledgements 31

3.0 - Using Carbon and Oxygen Isotopes to Monitor Water-Rock Interaction Under Simulated Geothermal Conditions in an Experimental Flow-Through System 32

3.1 - Introduction $\quad 32$

Development and Testing of the High-Temperature Flow-Through System 32

3.2 - Methods 36

3.3 - Results and Discussion $\quad 39$

$3.4-$ Conclusions $\quad 43$

4.0 - Appendix A - Figures and Tables 46

4.1 - Figures $\quad 46$

4.2 - Tables $\quad 54$

5.0 - References $\quad 57$ 


\section{List of Figures}

Figure 1: Map of Brady's well field as modified from Google Earth. 46

Figure 2: Depiction of the experimental pressure vessel systems showing (a) a simplified schematic of the experiments, (b) the low-temperature pressure vessel system, and (c) the high-temperature pressure vessel system

Figure 3: Carbon isotope shifts associated with water-rock interaction in the low-temperature (LT) and high-temperature (HT) static reactor experiments

Figure 4: Oxygen isotopic shifts associated with water-rock interaction in the low-temperature (LT) and high-temperature (HT) static reactor experiments

Figure 5: Carbon isotope mixing models depicting the percent contribution of the $\delta^{13} \mathrm{C}$ endmembers to the reacted fluid composition in the low-temperature (LT) and high-temperature (HT) static reactor experiments

Figure 6: Calcium concentration versus the saturation index with respect to calcite in the low-temperature (LT) and high-temperature (HT) static reactor experiments...

Figure 7: Sodium and potassium versus silicon concentrations in the low-temperature (LT) and hightemperature (HT) static reactor experiments.

Figure 8: Labeled photograph of the temperature controlled flow-through system ..............................50

Figure 9: Simplified schematic of the temperature controlled flow-through system

Figure 10: Labeled photographs showing the core holder components and assembly for the Morgantown-

NETL flow-through experiments

Figure 11: Carbon isotope shifts in the high-temperature core flow-through experiments corrected for $\mathrm{CO}_{2}$ degassing to show the extent of possible water-rock interaction.....

Figure 12: Oxygen isotope fluid composition in the high-temperature core flow-through experiments...53 


\section{List of Tables}

Table 1: Pre- and post-reaction isotopic compositions of solution and rock from the low- and hightemperature static reactor experiments

Table 2: Results from the two-endmember carbon isotope mixing model using data from the low- and

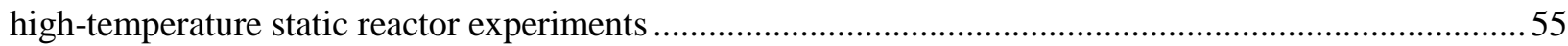

Table 3: Geochemical results from the low- and high--temperature static reactor experiments.................55

Table 4: Isotopic results from the high-temperature flow-through experiments and control tests ............56

Table 5: Geochemical results from the high-temperature flow-through experiments and control tests ....57 


\section{0 - Introduction}

Geothermal resources are a critical source of renewable energy with the potential to reduce our dependence on fossil fuels and decrease global $\mathrm{CO}_{2}$ emissions (Center for Climate Change and Energy Solutions, 2012; Fridleifsson et al., 2008; Tester et al., 2007). The concept of geothermal energy production is relatively simple but remains poorly understood by the public (Kuo, 2012; Tester et al., 2007). In its simplest terms, geothermal energy is thermal energy stored within the Earth's crust (Center for Climate Change and Energy Solutions, 2012; Fridleifsson, 2008; Green and Nix, 2006; Kuo, 2012; Stefansson, 2005; Tester et al. 2007). In order to generate electricity from geothermal resources, a series of injection and production wells are drilled into a target formation. Water is injected into a reservoir and heated by the host rock prior to extraction from production wells. The hot water extracted from the reservoir is then used to run turbines to generate electricity before it is re-injected into the reservoir.

Global geothermal energy resources have been estimated at $43 \times 10^{6} \mathrm{EJ}$ to a depth of $3 \mathrm{~km}$. With annual global energy consumption at only $420 \mathrm{EJ}$, there is a huge potential for geothermal exploration (Stefansson, 2005). Although the temperature is known to increase with depth, geothermal energy production has traditionally been limited to shallow hydrothermal reservoirs associated with the volcanic or tectonic activity. Three critical factors must be present for traditional hydrothermal resources to exist: (1) high temperature $\left(\geq 150^{\circ} \mathrm{C}\right)$, (2) fluid, and (3) permeability (Center for Climate Change and Energy Solutions, 2012; Fridleifsson et al.,2008; Green and Nix, 2006; Polsky, 2008; Stefansson, 2005; Tester et al., 2007). As a result, most of the energy considered in the estimate above is not economical for development without additional means of thermal energy extraction. 
Within the continental United States, areas of high heat flow are concentrated in the western half of the country with the exception of moderate temperature anomalies along the Gulf Coast and the Appalachian mountains. Although lower temperature resources $\left(\geq 100^{\circ} \mathrm{C}\right)$ can be used in direct use applications such as district heating and cooling, the depth of these resources limits their economic viability in much of the country. Adopting technology from the oil and gas industry and refining it for geothermal resource development could widely expand the economic geothermal energy potential of the United States. In order to develop geothermal resources outside of conventional hydrothermal systems, reservoirs must be engineered or enhanced using advanced drilling and hydraulic fracturing techniques. Geothermal reservoirs that require these techniques are referred to as Enhanced or Engineered Geothermal Systems (EGS) (Center for Climate Change and Energy Solutions, 2012; Fridleifsson et al., 2008; Green and Nix, 2006; Kuo, 2012; Polsky et al., 2008; Tester et al, 2007).

Research, development, and demonstration projects over the past 40 years have led to significant progress in developing EGS technology but additional research needs to be conducted for the widespread implementation of economic EGS. It is estimated that the incorporation of ongoing and future research in EGS could lead to the generation of $10 \%$ of the United States domestic energy supply (100 GW) by 2050 (Tester et al., 2006; DOE, 2016). Understanding the behavior of tight fracture networks in EGS both prior to and during stimulation and production is of critical importance for developing economically viable systems (Tester et al., 2007). In EGS, induced fracture networks are the major form of permeability in the rock and need to be understood to determine if sufficient flow is sustainable throughout the life of the system (Sanyal and Butler, 2005; Tester et al., 2007). The introduction of fluid into an EGS reservoir induces flow along fracture zones, which can alter the fracture properties of the rock. Fracture networks 
altered by water-rock interaction can impact reservoir permeability through mineral precipitation or dissolution. Therefore, understanding water-rock interactions in EGS is essential to ensure reservoir sustainability.

Previous work on predicting changes in fracture properties of EGS have predominately relied on numerical simulations such as Reactive Transport Models (RTMs) (Xu et al, 2004; Bachler and Kohl, 2005; Taron and Elsworth, 2010). RTMs are numerical simulations that determine chemical reactions as fluids are transported through rock. Developed in the 1980s, RTMs have been used extensively to understand interactions due to physical processes with a wide range of applications such as mineral dissolution, chemical weathering, and ion exchange; however, like all numerical models, RTMs relies on a number of assumptions that result in a prediction rather than a real-world solution. Therefore, development of a laboratory approach to monitoring waterrock interaction using stable isotopes may prove valuable in EGS assessments.

Isotopes are atoms of the same element that differ in mass based on the number neutrons present. Isotope ratios are expressed in delta notation $(\delta<0=$ depleted, $\delta>0=$ enriched $)$ and reported in permil (\%) based on the ratio of the heavy versus light isotopes (e.g. $\mathrm{R}={ }^{13} \mathrm{C} /{ }^{12} \mathrm{C}$ ) compared to that of an international standard (Clark and Fritz, 1997; Sharp, 2007).

$$
\delta=\left(R_{\text {sample }} / R_{\text {standard }}-1\right) \times 1000
$$

Carbon isotope ratios $\left(\delta^{13} \mathrm{C}\right.$ or $\delta^{13} \mathrm{C}$ DIC $)$ are measured against the international reference standard Vienna Pee Dee Belemnite (V-PDB). The stable isotopes of oxygen $\left({ }^{18} \mathrm{O}\right.$ and $\left.{ }^{16} \mathrm{O}\right)$ are expressed as $\delta^{18} \mathrm{O}$ and measured against Vienna Standard Mean Oceanic Water (V-SMOW) or V-PDB in water or rock, respectively. The following conversion can be used to compare $\delta^{18} \mathrm{O}$ in water and $\operatorname{rock} \delta^{18} O_{(V-P D B)}=0.97002 * \delta^{18} O_{(V-S M O W)}-29.98$. 
Isotopic variations occur due to fractionation processes that separate isotopes based on their mass. In equilibrium fractionation, isotopes exchange and redistribute towards equilibrium in a closed, well-mixed system. In kinetic fractionation, open systems allow preferential reaction, diffusion, or evaporation of one isotope over another resulting in larger isotopic shifts and more rapid fractionation rates when compared to that of equilibrium conditions (Clark and Fritz, 1997). Rayleigh distillation is the primary process that controls natural variations in $\delta^{18} \mathrm{O}$ and $\delta^{2} \mathrm{H}(\delta \mathrm{D})$. As evaporated water moves away from the ocean, successive rainfall events preferentially precipitate heavier isotopes resulting in an isotopic depletion trend in subsequent rain events. When carbonate minerals are dissolved in water, the isotopic signature of $\delta^{13} \mathrm{C}_{\text {DIC }}$ is dependent on the composition of source rock and fractionations associated with dissolution and DIC speciation (Clark and Fritz, 1997; Schulte et al, 2011). Furthermore, $\delta^{18} \mathrm{O}$ and $\delta^{13} \mathrm{C}$ withstand temperature dependent fractionations associated with calcite dissolution and precipitation.

Stable isotope geochemistry contributed significantly to the basic understanding of geothermal systems. A major advancement in the assessment of geothermal systems was made in 1963 when Harmon Craig found that geothermal systems are fed by meteoric water rather than water being derived from the magmatic origin. He noted that oxygen isotopes exchange with reservoir rocks at high temperatures while hydrogen isotopes remain unaffected due to the lack of hydrogen in the mineral structures of rock (Craig, 1963). Based on these effects, the hydrogen isotope composition of deep geothermal fluid can be sourced to local precipitation in the recharge area while oxygen isotopes are indicative of water-rock interaction (Craig, 1963; Qin et al., 2005). Subsequent studies have revealed that the isotopic composition of geothermal fluids can be impacted by additional processes such as mixing of fluids, hyperfiltration, boiling, and hydration 
of silicates (Giggenbach, 1992; Gonzalez-Partida, 2008; Phillips et al., 1986; Sanliyuksel and Baba, 2011; Simsek, 2003; Truesdell et al., 1977). Advancements in the application of isotope geochemistry in geothermal systems have made it possible to understand the recharge of thermal fluids, determine fluid fractionation processes, understand water-rock interaction, obtain reservoir temperatures, and date thermal fluids (Chiba and Sakai, 1985; Gonzalez-Partida et al, 2008; Inguaggiato et al, 2010; Phillips et al., 1986; Qin et al, 2005; Sanliyuksel and Baba, 2011; Simsek, 2003; Truesdell and Frye, 1977).

As hot water moves through a reservoir, isotopes exchange between the fluid and rock thereby altering their isotopic compositions. Water-rock interactions can occur through surface reactions (dissolution, precipitation, and recrystallization) or diffusional processes (surface diffusion, grain boundary diffusion and volume/lattice diffusion). When fluid and rock are out of equilibrium, surface reactions dominate the system but diffusion becomes the primary mechanism for isotopic exchange once equilibrium is attained (Cole and Chakraborty, 2001). In EGS applications where the fluid and rock are out of equilibrium with one another, surface reactions dominate the system. For the isotopic exchange to occur between geothermal fluids and rocks, the two phases must be in contact and react with one another as seen in the surface reaction $\mathrm{Ca}^{13} \mathrm{CO}_{3}+\mathrm{H}_{2} \mathrm{CO}_{3}$ $\leftrightarrow \mathrm{CaCO}_{3}+\mathrm{H}_{2}{ }^{13} \mathrm{CO}_{3}$

Several additional factors can influence the isotope exchange rate and fractionation associated with water-rock interactions including the isotopic exchange mechanism, the water/rock ratio, temperature, pressure, surface area, and fluid and mineral composition (Cole and Chakraborty, 2001; Cole et al., 1987). The isotopic fractionation rate is affected by the isotopic exchange mechanism, as diffusional processes are much slower than surface reactions at temperatures less than 500 C (Anderson and Chai, 1974; Cole and Chakraborty, 2001; Cole et al., 1983; Cole et 
al., 1987; Cole, 1999). The water to rock ratio affects isotopic exchange by altering the composition of the fluid and rock in proportion to the ratio of the fluid to rock present. For instance, when the water/rock ratio is low, the isotopic composition of the fluid becomes significantly altered while the composition of the rock does not change appreciably (Clark and Fritz, 1997; Sharp, 2007; Qin et al., 2005). The degree of carbon isotope exchange depends less on the water-rock ratio and more the fluids ability to dissolve or precipitate carbonate minerals as well as the relative amount of carbon in the fluid and rock. For example, dissolution of calcite in a fluid with a low DIC concentration will affect the carbon isotopic composition of the solution more appreciably than if the DIC concentration were initially high. The water/rock ratio also plays an important role in the rate of isotopic exchange. As the water/rock ratio decreases, the time required to obtain equilibrium also decreases (Cole et al., 1983).

The temperature associated with a geothermal system plays a vital role in determining the waterrock interaction (Cole and Chakraborty, 2001; Cole et al., 1983; Cole et al., 1987; Ligang et al., 1989; Qin et al, 2005; Zheng, 1999). Minerals exchange or react with geothermal water at different temperatures resulting in an isotopic fractionation. This shift in isotopic values is a function of temperature. In geothermal systems with temperatures $<250^{\circ} \mathrm{C}$, silicate mineral reactions are often too small to result in measurable isotopic shifts, while the carbon and oxygen isotopes exchange with carbonate minerals at temperatures less than $100^{\circ} \mathrm{C}$ (Cole et al., 1983 ; Matthews et al., 1979; Ligang et al., 1989; Qin et al, 2005; Zheng, 1999). Furthermore, isotopic exchange rates are influenced by temperature and pressure. As temperature and/or pressure in a system increase, the rate of isotopic exchange also increases (Cole and Chakraborty, 2001; Zheng, 1999). However, calcite-water fractionation is known to depend less on temperature than a silicate-water system (Qin et al., 2005). Finally, fluid composition affects fractionation and 
exchange rates as the addition of salts may increase the solubility and dissolution rates with respect to some minerals (Cole and Chakraborty, 2001).

\section{1 - Site Description \& Project History}

Brady's Hot Springs is a hydrothermal field in western Nevada about $80 \mathrm{~km}$ east of Reno (Figure 1). Marked by a $4 \mathrm{~km} \mathrm{NNE}$ trending surface expression of sinter, warm ground, fumaroles, and mudpots, Brady's Field has long been known for its geothermal resources. Several phases of geothermal development have been ongoing at Brady's Hot Springs since the 1880s (Ettinger and Brugman, 1992; Nevada Bureau of Mines and Geology, 2013). The site was successfully developed for electricity generation in 1992 when the Western States Geothermal Company began operation of a $26 \mathrm{MW}$ dual flash power plant. An additional $5 \mathrm{MW}$ binary unit was installed in 2001 after the site was purchased by ORMAT Nevada, Inc., thereby increasing electrical capacity on site (Nevada Bureau of Mines and Geology, 2013; Ettinger and Brugman, 1992).

Nevada is home to an abundance of geothermal systems and is the second largest state in terms of geothermal energy production. While volcanic activity ceased in the region between 3 and 10 million years ago, a series of fault zones give rise to the state's geothermal resources (Kratt et al, 2006; Faulds et al, 2004; Faulds et al, 2010). Four NNE trending fault zones associated with Basin and Range extension run in parallel across the state (Sevier Desert, Humboldt Structural Zone, Black Rock Desert, and Surprise Valley fault zones). A fifth major fault zone (Walker Lane), dominated by a series of right-lateral strike-slip faults that accommodate about $20 \%$ of the motion between the Pacific and North American plates, trends NW along the western border of the state (Faulds et al, 2004; Faulds et al, 2010). Brady's Hot Springs is located within the Humboldt Structural Zone near its intersection with the Walker Lane. Characterized by a series 
of NNE trending en echelon normal faults, the geothermal field is highly faulted with high fluid transmissivity throughout much of the system.

Six production wells, ranging in depth from 400 to $1850 \mathrm{~m}$, currently drive hydrothermal power generation in the step-over normal fault system at Brady's Field (Ali et al, 2015). Hot water is extracted from the hydrothermal system with bottom hole temperatures ranging from $172-205^{\circ} \mathrm{C}$ (Ali et al, 2015; Bromhal et al., 2011; Ettinger and Brugman, 1992). In 2007, a deep high temperature well (15-12) was drilled adjacent to the hydrothermal field to a total depth of 1553 $\mathrm{m}$. Injection tests of 15-12 indicated a lack of permeability and connectivity to the hydrothermal system. In 2008, the U.S. Department of Energy funded an EGS demonstration project at Brady's Field to characterize and stimulate the reservoir in an attempt to improve injectivity and establish connectivity with the hydrothermal system (Drakos, 2010; Lutz et al, 2011). To understand the subsurface properties of the EGS well, a deep monitoring well (BCH-03) was drilled adjacent to 15-12 to a depth of $1487 \mathrm{~m}$ at the southern edge of Brady's field (Figure 1) (Crandall et al, 2014; Lutz, 2011).

This thesis was part of a larger collaborative research effort with the National Energy Technology Laboratory (NETL), Penn State, the University of Pittsburgh, and West Virginia University (WVU) in which RTM (CrunchFlow) and a series laboratory experiments were conducted to evaluate water-rock interaction using cores from Brady's Field Well BCH-03. Specifically, a series of experimental methods were developed and tested to monitor water-rock interactions with stable isotopes, radiogenic isotopes, and geochemistry under high pressure and temperature conditions. As part of this study, cores from $\mathrm{BCH}-03$ were analyzed for fracture properties and three target depths were selected for investigation $(1358,1396$, and $1459 \mathrm{~m})$. Prior to this study, a comprehensive characterization of the cores was conducted to assess the 
mineralogy of the rock. The major lithology of the target reservoir is a Jurassic meta-volcanic rock with a series of complex veins. Based on XRD analysis, the mineralogy of the samples vary with depth but are predominately composed of quartz and illite/muscovite with plagioclase at shallower depths and minor to trace amounts of chlorite, calcite, and rutile throughout (Bromhal et. al., 2011; Crandall et al, 2014).

This thesis was designed to test the feasibility of using carbon and oxygen isotopes to monitor water-rock interactions under geothermal conditions. Three experimental systems are the basis for all research discussed in this thesis. Using cores from Brady's Field Well BCH-03, investigations were conducted in a series of high-temperature pressure vessels and a hightemperature flow-through system in which a calcium bicarbonate solution was exposed to metavolcanic rocks from up to three target depths $(1358,1396$, and $1459 \mathrm{~m})$. An initial set of experiments were conducted in a series of low-temperature static pressure vessels at NETL prior to the implementation of a high-temperature static pressure vessel system at WVU. The static reactor experiments were conducted for $14-20$ days at $90-144^{\circ} \mathrm{C}$ and 120 bar. A high-temperature flow-through system was also developed and tested at the Morgantown NETL as part of this thesis. The flow-through system enabled continuous flow of fluid through sub-cores from well BCH-03 under relevant geothermal conditions. Flow-through experiments were conducted for 14 days at $144^{\circ} \mathrm{C}$ and 103 bar pore-pressure. Although temperatures in the field at the EGS target depths can be as high as $172-205^{\circ} \mathrm{C}$, laboratory temperatures were constrained by experimental capabilities.

As water-rock interaction occurs, the isotopic compositions of the solution and rock are altered by isotopic exchange processes. Since the initial fluid and rock compositions are out of equilibrium with one another in the experiments, surface reactions were expected to be the 
dominant isotopic exchange process during water-rock interaction as would be expected in most field scale EGS applications. Using distinct isotopic endmembers, changes in the isotopic composition of the reacted fluid may be used to monitor water-rock interaction. However, despite to the abundance of oxygen in the rock, temperature limitations of the experimental systems make it unlikely for significant water-silicate oxygen isotope exchange to take place. Because carbon and oxygen isotopes exchange with calcite at lower temperatures, carbonate reactions were expected to control isotopic shifts in the solution. Due to the large volume of fluid circulation required for economic EGS, a relatively high water-rock ratio (24:1) was used in the experiments. With limited calcite in the cores from $\mathrm{BCH}-03$ and a high water to rock ratio, shifts in $\delta^{18} \mathrm{O}$ associated with calcite dissolution were expected to be minimal due to the abundance of oxygen present in solution. However, $\delta^{13} \mathrm{CDIC}_{\mathrm{DI}}$ shifts associated with calcite dissolution were expected to dominate the system due to the limited initial concentration of DIC in solution. Although isotopic shifts in the rock could occur with mineral precipitation, the initial composition of the calcium bicarbonate solution in the experiments was thought to favor calcite dissolution. Because reacted rock is not readily recovered from EGS systems and isotopic fluid shifts are expected to dominate the experimental reactions, the reacted fluid composition was the focus of this study.

\section{2 - Format of Thesis}

Chapter 1 of this paper contains background information related to geothermal energy, isotope applications in geothermal systems, site characterization information, and the scope of this study. Chapter 2 includes a comprehensive manuscript of the static reactor experiments for potential submission to a scientific journal and Chapter 3 describes the development and testing of an experimental flow-through system as part of this research. 


\title{
2.0 Using Carbon and Oxygen Isotopes to Monitor Water-Rock Interaction Under Simulated Geothermal Conditions in Static Pressure Vessel Systems
}

\author{
Abstract \\ Engineered or Enhanced Geothermal Systems (EGS) have the potential to unlock vast high- \\ temperature energy resources that lack the natural permeability and fluid required to generate \\ sufficient high-temperature fluids for power generation. In order to ensure sustained fracture \\ connectivity in an EGS, water-rock interactions must be understood in high temperature and \\ pressure systems. Using cores from Brady’s Field Well BCH-03, investigations were conducted \\ to test the feasibility of using carbon and oxygen isotopes to monitor water-rock interactions \\ under simulated geothermal conditions. Reactions were examined in a series of batch \\ experiments under elevated temperature and pressure conditions in which a calcium bicarbonate \\ solution was exposed to meta-volcanic rocks from three target depths (1358, 1396, and $1459 \mathrm{~m})$. \\ Experiments were conducted for $14-20$ days at $90-144^{\circ} \mathrm{C}$ and 120 bar. Water samples were \\ collected before and after each experiment for isotopic and geochemical analyses. The isotopic \\ results revealed significant enrichments of $\delta^{13} \mathrm{C}_{\mathrm{DIC}}$ in the solution, while $\delta^{18} \mathrm{O}_{\mathrm{H} 2 \mathrm{O}}$ remained \\ unaffected by water-rock interaction. Geochemical results of post-reaction samples demonstrated \\ a decline in calcium and alkalinity concentrations with an increase in sodium, potassium, and \\ silica concentrations. The results indicate that the calcium bicarbonate solution, undersaturated \\ with calcite, drove initial calcite dissolution in the rock. As the temperature increased and the \\ solubility of $\mathrm{CO}_{2}$ declined, the solution became oversaturated with calcite, leading to $\mathrm{CO}_{2}$ \\ degassing and subsequently calcite precipitation. The lack of measurable $\delta^{18} \mathrm{O}$ shifts can be \\ attributed to the abundance of oxygen in the solution that constrained the impact of water-rock \\ interaction. The $\delta^{13} \mathrm{C}_{\text {DIC }}$ results indicate the presence of significant calcite dissolution in all
}


experiments with carbon isotope mixing models suggesting a 37.8 to $54.6 \%$ contribution of $\delta^{13} \mathrm{C}$ from the rock in the post-reaction fluid. Although early-stage calcite dissolution may have temporarily increased the calcium and alkalinity concentrations in solution, the effects of $\mathrm{CO}_{2}$ degassing and subsequent calcite precipitation dominate the geochemical results. The geochemical data also suggests the presence of silicate mineral reactions not observed in the isotopic results.

\section{1 - Introduction}

Engineered or Enhanced Geothermal Systems (EGS) research has been rapidly expanding since the early 1970s when the United States Department of Energy (DOE) funded the Fenton Hill hot dry rock experiments. Although significant progress has been achieved over the past 40 years, additional research needs to be conducted for the widespread implementation of economic EGS (Tester et al. 2007). With global geothermal energy estimated at $43 \times 10^{6} \mathrm{EJ}$ at $\leq 3 \mathrm{~km}$ depth and global energy consumption at 420 EJ annually, geothermal energy represents a massive renewable energy resource with the potential to reduce our dependence on fossil fuels (Stefansson, 2005). However, current geothermal energy production is limited to hydrothermal systems where natural heat, permeability, and fluid are present for resource utilization. By adopting drilling and hydraulic fracturing techniques from the oil and gas industry and refining them for EGS resource development, the economic geothermal energy potential of the United States could be widely expanded.

Understanding the behavior of tight fracture networks in EGS both prior to and during stimulation and production is of critical importance for developing economically viable systems. In EGS systems, induced fracture networks are the major form of permeability in the rock and need to be understood to determine if sufficient flow is sustainable throughout the life of the 
system (Sanyal and Butler, 2005; Tester et al., 2007). The introduction of fluid into an EGS induces flow along fracture zones and can alter fracture permeability through mineral precipitation or dissolution (Sanyal and Butler, 2005). This study focuses on the use of stable isotopes and fluid geochemistry in laboratory geothermal systems to understand and predict water-rock interactions in EGS fracture networks prior to stimulation and production.

Studies have shown that oxygen isotopes exchange with reservoir rocks at high temperatures while hydrogen isotopes remain unaffected by water-rock interaction (Craig, 1963). Although not commonly applied to monitor water-rock interactions in geothermal systems, carbon isotopes may also be effective tracers for water-rock interaction in the presence of carbonate minerals. In geothermal systems, the isotopic exchange rate and degree of fractionation associated with water-rock interactions can be influenced by a number of factors including the water/rock ratio, temperature, pressure, surface area, and solution and mineral composition (Clark and Fritz, 1997; Cole and Chakraborty, 2001; Cole et al., 1983; Cole et al., 1987; Ligang et al., 1989; Matthews et al., 1979; Sharp, 2007; Zheng, 1999). In addition to these controls, it is important to note that the isotopic composition of geothermal fluids can also be impacted by mixing, hyperfiltration, boiling, degassing, and hydration of silicates (Giggenbach, 1992; Gonzalez-Partida, 2008; Phillips et al., 1986; Sanliyuksel and Baba, 2011; Simsek, 2003; Truesdell et al., 1977).

\section{Site Description and Experimental Setup}

Brady's Hot Springs is a geothermal field in western Nevada about $80 \mathrm{~km}$ east of Reno (Figure 1). Located within the Humboldt Structural Zone near its intersection with the Walker Lane, Brady's Field is characterized by a step-over in a series of NNE trending en echelon normal faults that give rise to high fluid transmissivity in the hydrothermal system. Brady's Field has a 
long history of geothermal resource development that includes the operation of a $26 \mathrm{MW}$ dual flash power plant and 5 MW binary unit (Ettinger and Brugman, 1992; Nevada Bureau of Mines and Geology, 2013).

Six production wells ranging in depth from 400 to $1850 \mathrm{~m}$ currently drive hydrothermal power generation in the step-over normal fault system at Brady's Field (Ali et al, 2015). Hot water is extracted from the hydrothermal system with bottom hole temperatures ranging from $172^{\circ} \mathrm{C}$ to $205^{\circ} \mathrm{C}$ (Ali et al, 2015; Bromhal et al., 2011; Ettinger and Brugman, 1992). In 2007, a deep high temperature $\left(204^{\circ} \mathrm{C}\right)$ production well, well $15-12$, was drilled adjacent to the hydrothermal field to a depth of $1553 \mathrm{~m}$ (Lutz et al, 2011). Injection tests of 15-12 indicated a lack of permeability and connectivity to the hydrothermal system. In 2008, the U.S. Department of Energy funded an EGS demonstration project at Brady's Field to characterize and stimulate the reservoir in an attempt to improve injectivity and establish connectivity with the hydrothermal system (Drakos, 2010; Lutz et al, 2011). To understand the subsurface properties of the nearby EGS well, a deep monitoring well (BCH-03) was drilled to a depth of $1487 \mathrm{~m}$ at the southern edge of Brady's field (Crandall et al, 2014; Lutz et al, 2011). Cores from well BCH-03 were preserved for analysis and serve as the basis for this study.

Using cores from Brady's Field well BCH-03, three target depths were selected for testing and analysis $(1358,1396$, and 1459m). The geothermal reservoir is composed of a Jurassic metavolcanic rock with a series of complex veins (Lutz et al, 2011). The mineralogy at the depths targeted for this study vary slightly but are predominately composed of quartz and illite/muscovite with a significant amount of plagioclase at $1358 \mathrm{~m}$ and minor to trace amounts of chlorite, calcite, and rutile throughout (Bromhal et al., 2011; Crandall et al, 2014). 
The purpose of this study was to test the feasibility of using carbon and oxygen isotopes in conjunction with geochemical data to monitor water-rock interactions in laboratory geothermal systems to understand and predict reservoir sustainability in an EGS. Using the rock from each target depth, reactions were observed under geothermal conditions in which a calcium bicarbonate solution was exposed to powdered and crushed rock. Experiments were conducted for $14-20$ days at $90-144^{\circ} \mathrm{C}$ and 120 bar. Although temperatures at the target depths are expected to be as high as $172-205^{\circ} \mathrm{C}$ in the field, laboratory temperatures were constrained by experimental capabilities. An initial set of experiments were conducted in a series of lowtemperature static pressure vessels at the National Energy Technology Laboratory (NETL) prior to the implementation of the high-temperature static pressure vessel system at West Virginia University. Water and rock samples were collected before and after each experiment for isotopic and geochemical analyses. By using distinct isotope endmembers, results were analyzed for shifts associated with water-rock interaction with careful consideration of experimental error and isotopic fractionation processes.

Under the experimental conditions, calcite was expected to be the most reactive mineral in the system. When carbonate minerals dissolve and precipitate, the isotopic composition of the reacted solution depends on the degree of water-rock interaction as well as the isotopic fractionations associated with dissolution, precipitation, and $\mathrm{pH}$-dependent DIC speciations (Clark and Fritz, 1997; Deines et. al., 1974; Kjartansdóttir, 2014; Schulte et al, 2011). If the pH of the solution remains in the bicarbonate range, $\mathrm{CaCO}_{3} \leftrightarrow \mathrm{HCO}_{3}{ }^{-}$fractionation of $\delta^{13} \mathrm{C}$ and $\mathrm{CaCO}_{3} \leftrightarrow \mathrm{H}_{2} \mathrm{O}$ fractionation of $\delta^{18} \mathrm{O}$ will dominate these effects. However, the temperature and $\mathrm{pH}$ dependent isotopic fractionation factors must be understood to quantify isotopic shifts associated with the water-rock interaction. 


\section{2 - Methods}

In order to observe water-rock interactions, the composition of the fluid must be isotopically distinct from the rock with respect to both carbon and oxygen isotopes. Using cores from Brady's Field Well BCH-03, an isotopic characterization of the cores was conducted to assess the isotopic composition and heterogeneity of the rock samples. With the isotopic composition of the rock defined, a calcium bicarbonate solution was selected for experimentation to observe water-rock interactions in a simple carbon bearing solution. The calcium bicarbonate solution was synthesized by adding $2.5 \mathrm{~g}$ of Calcium Carbonate $\left(\delta^{13} \mathrm{C}=-8.65 \%\right)$ and dry ice $\left(\delta^{13} \mathrm{C} \sim\right.$ $40 \%$ ) to 5 gallons of deionized water. The dry ice was added to the solution to ensure a distinct $\delta$

${ }^{13} \mathrm{C}_{\mathrm{DIC}}$ composition and aid in $\mathrm{CaCO}_{3}$ dissolution. The solution was equilibrated for 24 hours before passing through a $0.4 \mu \mathrm{m}$ filter to eliminate undissolved $\mathrm{CaCO}_{3}$. The resulting solution dissolved approximately $1.27 \mathrm{~g}$ of $\mathrm{CaCO}_{3}$ in solution for an initial concentration of $67 \mathrm{mg} / \mathrm{L}$ $\mathrm{CaCO}_{3}$.

Using cores from Brady's Field Well BCH-03, investigations were conducted in a series of heated pressure vessels in which calcium bicarbonate solution was exposed to rocks from three target depths $(1358,1396$, and $1460 \mathrm{~m})$. The experiments were conducted in low-temperature $\left(90^{\circ} \mathrm{C}\right) 1$-liter static pressure vessels at the NETL and high temperature $\left(144^{\circ} \mathrm{C}\right) 600 \mathrm{ml} \mathrm{static}$ pressure vessels at WVU. In each experiment, $240 \mathrm{~g}$ of calcium bicarbonate solution, $7.5 \mathrm{~g}$ powdered rock, and $2.5 \mathrm{~g}$ of rock chips were added to a Teflon sample cup in the reactors for a water-rock ratio of 24:1. Powdered and crushed rock was used to maximize the surface area and encourage water-rock interaction due to the short experimental durations. The remaining volume of each pressure vessel was filled with $\mathrm{N}_{2}$ and pressurized to 120 bar. In order to minimize residual atmospheric $\mathrm{CO}_{2}$ in the system, the reactors were flushed with three volumes of $\mathrm{N}_{2}$ prior 
to pressurization. Once the pressure was attained, the reactors were heated to $90^{\circ} \mathrm{C}$ and $144^{\circ} \mathrm{C}$ in the low- and high-temperature systems, respectively.

Using the methods described above, three experiments were conducted in April 2014 in which rocks from the 1358, 1396, and $1460 \mathrm{~m}$ depths were reacted for 16 days in the low-temperature system. Following the procurement and setup of the high-temperature pressure vessel system, additional experiments were conducted in December 2014 in which rocks from 1358 and $1396 \mathrm{~m}$ depths were reacted for 15 and 19 days, respectively. In the high-temperature reactor system, controls were conducted alongside each experiment in which $240 \mathrm{~g}$ of calcium bicarbonate solution was added to a reactor without the presence of rock to assess potential isotopic fractionation and geochemical shifts associated with the experimental system. Aside from the lack of rock in the reactors, the controls were conducted using the same methods described for the high-temperature experiments.

Due to the design of the pressure vessel systems it was not possible to collect samples during the experiment, therefore sampling was limited to pre- and post-reaction. Pre-reaction rock samples were dried, weighed, and stored in small centrifuge containers for isotopic analysis prior to each experiment to constrain the solid endmember composition. Pre and post-reaction fluid samples were collected for isotopic and geochemical analyses immediately before and after each experiment to limit atmospheric exposure of the fluid. Duplicate fluid samples were taken when possible. Isotopic fluid samples were collected via a gas-tight syringe and injected into multiple sample vials through a $0.45 \mu \mathrm{m}$ nylon filter to eliminate suspended solids. Sample vials were flushed with helium and $\mathrm{CO}_{2}$ in helium mix prior to sample collection for carbon and oxygen isotope analysis, respectively. Geochemical samples were collected and preserved in accordance with the NETL Pittsburgh Analytical Lab protocol for cations, anions, alkalinity, and $\mathrm{pH}$. 
For carbon isotope analysis of pre- and post-reaction fluids, $0.1 \mathrm{ml}$ of phosphoric acid (80\%) was added to each sample in the helium flushed vials and equilibrated for 24 hours prior to analysis. Pre- and post-reaction fluid samples in the $\mathrm{CO}_{2}$ in helium mix flushed vials were equilibrated in excess of 24 hours prior to oxygen isotope analysis. Homogenized solids were weighed to approximately $0.5 \mathrm{mg}$ in sample vials and dried overnight at $50^{\circ} \mathrm{C}$ in preparation for carbon and oxygen isotope analysis. The solid filled vials were then flushed with helium, acidified with 0.1 $\mathrm{ml}$ of phosphoric acid (80\%), and equilibrated for 24 hours prior to analysis. The $\mathrm{CO}_{2}(\mathrm{~g})$ released from the fluid or rock in each sample was analyzed for $\delta^{13} \mathrm{C}$ and $\delta^{18} \mathrm{O}$ with a Finnigan Delta Advantage continuous flow Isotope Ratio Mass Spectrometer via a PAL autosampler system at the West Virginia University Stable Isotope Laboratory (WVUSIL).

Geochemical fluid samples were analyzed at the NETL Pittsburgh Analytical Lab for cations, anions, and alkalinity. Geochemical analyses were conducted via alkalinity titration, Ion Chromatography (IC), Inductively Coupled Plasma Mass Spectrometry (ICP-MS), and Inductively Coupled Plasma Optical Emission Spectroscopy (ICP-OES). All samples were measured for $\mathrm{pH}$ prior to sample collection and laboratory analysis. Geochemical characterization of the rock samples from these experiments were not conducted as part of this study.

\section{3 - Results}

In all experiments, the fluid and rock endmembers were isotopically distinct with respect to $\delta^{13} \mathrm{C}$ and $\delta^{18} \mathrm{O}$ (Table 1). Despite variations in the isotopic composition of endmembers in the two experimental systems, the isotopic trends associated with the water-rock interaction remained the same. As water-rock interaction occurred, significant enrichments in $\delta^{13} \mathrm{C}_{\text {DIC }}$ were observed while $\delta^{18} \mathrm{O}_{\mathrm{H} 2 \mathrm{O}}$ remained unaffected by the water-rock interaction (Table 1). Isotopic 
compositions of the endmembers and reacted solutions from the low- and high-temperature static reactor experiments and control tests are presented below and can be found in Table 1. The stable isotope ratios of $\delta^{13} \mathrm{C}$ and $\delta^{18} \mathrm{O}$ are reported in per mil (\%) relative to the international reference standard Vienna Pee Dee Belemenite (V-PDB).

In the low-temperature static reactor experiments, the initial $\delta^{13} \mathrm{C}_{\text {DIC }}$ composition of the calcium bicarbonate solution was $-39.8 \%$ while the $\delta^{13} \mathrm{C}$ endmember compositions of the rock varied with depth from -7.0 to $-8.9 \%$. Following the low-temperature reactions, the $\delta^{13} \mathrm{C}_{\mathrm{DIC}}$ composition of the reacted calcium bicarbonate solutions ranged from -21.7 to $-25.4 \%$.

In the high-temperature static reactor experiments, the initial $\delta^{13} \mathrm{C}_{\mathrm{DIC}}$ composition of the calcium bicarbonate solution ranged from -22.4 to $-22.6 \%$ while the $\delta^{13} \mathrm{C}$ endmember composition of the rock varied with depth from -8.7 to $-9.3 \%$. In the post-reaction samples, the $\delta^{13} \mathrm{C}_{\mathrm{DIC}}$ composition of the calcium bicarbonate solution ranged from -13.0 to $-14.7 \%$. In the control tests run alongside the high-temperature experiments, the final $\delta^{13} \mathrm{C}_{\mathrm{DIC}}$ composition of the calcium bicarbonate solutions ranged from -20.9 to $-21.4 \%$.

The $\delta^{18} \mathrm{O}$ composition of the unreacted calcium bicarbonate solution in the low-temperature experiments was $-39.7 \%$ while the endmember composition of the rock varied with depth from 20.0 to $-20.9 \%$. The $\delta^{18} \mathrm{O}$ composition of low-temperature post-reaction fluid samples ranged from $-39.2 \%$ to $-39.3 \%$.

In the high-temperature experiments, the $\delta^{18} \mathrm{O}$ endmember composition of the calcium bicarbonate solution was $-39.6 \%$ and the endmember composition of the rock varied with depth from -20.4 to $-21.7 \%$. In the post-reaction samples from the high-temperature pressure vessel 
system, the $\delta^{18} \mathrm{O}$ composition of the calcium bicarbonate solution ranged from $-39.4 \%$ to $39.5 \%$ in the experiments and $-39.4 \%$ to $-39.6 \%$ in the control tests.

The calcium and alkalinity concentrations of the unreacted calcium bicarbonate solution ranged from 24-26 mg/l and 71-96 mg/l as $\mathrm{CaCO}_{3}$, respectively (Table 3). However, it is important to note that geochemical sampling of the unreacted fluid from the low-temperature experiments was conducted after a significant lag time following the experiments and likely underestimates calcium, alkalinity, and the saturation index with respect to calcite due to $\mathrm{CO}_{2}$ degassing through time. Aside from the presence of calcium and alkalinity, the initial solutions demonstrated a lack of dissolved ions.

The calcium concentrations in the post-reaction fluid samples from the low- and hightemperature experiments ranged from 14.5 to $19.6 \mathrm{mg} / \mathrm{l}$ with the exception of the $1396 \mathrm{~m}$ hightemperature reaction in which the post-reaction calcium concentration was $58.1 \mathrm{mg} / \mathrm{l}$. The alkalinity concentrations in the reacted solutions ranged from 205 to $369 \mathrm{mg} / \mathrm{l}$ as $\mathrm{CaCO}_{3}$ in the low-temperature experiments and 79 to $83 \mathrm{mg} / \mathrm{l}$ as $\mathrm{CaCO}_{3}$ in the high-temperature experiments. In the high-temperature control tests, the calcium and alkalinity concentrations in the final solutions ranged from 16.6 to $19.4 \mathrm{mg} / \mathrm{l}$ and 44 to $65 \mathrm{mg} / \mathrm{l}$ as $\mathrm{CaCO}_{3}$, respectively.

Using geochemical data from the low- and high-temperature static reactor experiments, the saturation index with respect to calcite $\left(\mathrm{SI}_{\text {calcite }}\right)$ was calculated using the equation $\mathrm{SI}_{\text {calcite }}=$ $\log (\mathrm{IAP}) / \mathrm{Ksp}$ in which IAP is the Ion Activity Product and Ksp is the temperature dependent solubility product of calcite (Panthi, 2003; Stumm and Morgan, 1996; and Wojtowicz, 2001). Throughout the experiments, the $\mathrm{SI}_{\text {calcite }}$ increased from an initial range of -1.4 to -1.7 to a post- 
reaction range of 0.9 to 1.7 . In the high-temperature control tests, the $\mathrm{SI}_{\text {calcite }}$ also increased from an initial value of -1.4 to a post-reaction range of 0.1 to 0.3 .

Significant changes were also observed in the post reaction fluid from the low- and hightemperature experiments with respect to $\mathrm{Si}, \mathrm{Na}$, and $\mathrm{K}$. In the low-temperature experiments, the Si concentrations in the reacted fluid ranged from 15.8 to $24.5 \mathrm{mg} / \mathrm{l}$ while $\mathrm{Na}$ and $\mathrm{K}$ concentrations ranged from 23.4 to $43.7 \mathrm{mg} / \mathrm{l}$ and 82.5 to $115 \mathrm{mg} / \mathrm{l}$, respectively. In the postreaction solutions from the high-temperature experiments, the $\mathrm{Si}, \mathrm{Na}$, and $\mathrm{K}$ concentrations varied from 33.2 to $57.3 \mathrm{mg} / \mathrm{l}, 9.4$ to $20.7 \mathrm{mg} / \mathrm{l}$, and 4.9 to $11.9 \mathrm{mg} / \mathrm{l}$, respectively. In the hightemperature control tests, $\mathrm{Si}, \mathrm{Na}$, and $\mathrm{K}$ were undetected in both the initial and final samples.

\section{4 - Discussion}

In the low- and high-temperature static reactor experiments, distinct isotopic and geochemical endmembers were used to assess the feasibility of monitoring water-rock interactions in high temperature and pressure laboratory geothermal systems using carbon and oxygen isotopes. A calcium bicarbonate solution was prepared with a depleted $\mathrm{CO}_{2}$ source $\left(\delta^{13} \mathrm{C}_{\mathrm{CO} 2} \sim-40 \%\right.$ o $)$ to ensure it was isotopically distinct from the isotopic signatures of the rock from Brady's Field well BCH-03

However, several challenges emerged when using $\mathrm{CO}_{2}$ saturated solutions for monitoring waterrock interaction in high pressure and temperature laboratory systems. As the temperature of a solution increases, the solubility of $\mathrm{CO}_{2}$ decreases significantly, leading to the possibility of $\mathrm{CO}_{2}$ degassing in the system. Furthermore, depressurization of the system prior to fluid sampling may result in further degassing during sample collection (Kaszuba, et. al., 2013; and Pistone et al., 2011). As $\mathrm{CO}_{2}$ degasses from a solution, lighter isotopes preferentially degas resulting in 
isotopic enrichment of the solution. Due to the abundance of oxygen in the water solution with limited DIC, the isotopic effect of $\mathrm{CO}_{2}$ degassing was expected to be more pronounced in the $\delta^{13} \mathrm{C}_{\text {DIC }}$ compared to $\delta^{18} \mathrm{O}_{\mathrm{H} 2 \mathrm{O}}$. To understand the impact of these effects, control experiments were conducted using the high-temperature static pressure vessel system.

In both the low- and high-temperature experiments, similar trends were observed as water-rock interaction occurred. With calcite as the most reactive mineral in the target depths, carbonate reactions were expected to dominate the water-rock interaction in the system. During calcite dissolution, the isotopic composition of the solution shifts towards that of the composition of the rock endmember. Due to the limited concentration of DIC in solution, the isotopic shift in $\delta^{13} \mathrm{C}_{\text {DIC }}$ was anticipated to be more pronounced than $\delta^{18} \mathrm{O}_{\mathrm{H} 2 \mathrm{O}}$.

\section{Carbon and Oxygen Isotopes}

With calcite dissolution and precipitation expected to drive water-rock interaction under the experimental temperatures, carbon isotopic shifts are the major focus of the results from this study. In order to observe shifts in $\delta^{13} \mathrm{C}$, a large reservoir of the calcium bicarbonate solution was created prior to experimentation in an effort to maintain a distinct and consistent fluid endmember composition throughout the experiments. However, isotopic analysis of the fluid end member through time revealed a significant $\delta^{13} \mathrm{C}_{\mathrm{DIC}}$ enrichment trend during the eight-month lag time between the experiments. From April 2014 to December 2014, the $\delta^{13} C_{\text {DIC }}$ composition of the fluid endmember became enriched by $+17.4 \%$ due to preferential degassing of lighter $\mathrm{CO}_{2}$ from the solution. Despite the carbon isotope enrichment trend, the endmember composition of the calcium bicarbonate solution remained isotopically distinct from the solid endmembers throughout all experiments. 
Upon discovery of the $\mathrm{CO}_{2}$ degassing trend, investigations were carried out to assess the potential carbon isotopic shifts associated with $\mathrm{CO}_{2}$ degassing during experimentation. In order to constrain $\mathrm{CO}_{2}$ degassing in the experiments, control tests were conducted alongside each experiment in the high-temperature pressure vessel system. Using the results from the control tests, a correction factor of $-1.4 \%$ was calculated and applied to the post-reaction fluid composition to quantify probable $\delta^{13} \mathrm{C}_{\mathrm{DIC}}$ shifts associated with water-rock interaction alone. Although this correction is likely to be a good estimate of the impact of $\mathrm{CO}_{2}$ degassing in the high-temperature experiments, it may not accurately assess this effect in the low-temperature experiments due to the elevated $\mathrm{CO}_{2}$ concentrations at the onset of the experiments.

Variations in the results from two the experimental systems are largely associated with differences in the endmember compositions of the fluid and rock. However, despite the endmember variations, similar trends are observed in both experimental systems. In the experiments, significant enrichments in $\delta{ }^{13} \mathrm{C}_{\mathrm{DIC}}$ of the solutions were observed with limited depletions of $\delta{ }^{13} \mathrm{C}$ in the rocks. Although these isotopic shifts are largely associated with the water-rock interaction, enrichments in $\delta{ }^{13} \mathrm{C}_{\mathrm{DIC}}$ of the solutions were corrected to account for $\mathrm{CO}_{2}$ degassing.

The carbon isotope results presented in Figure 3 differ between the experimental systems based on the endmember compositions and the degree of water-rock interaction. Since the endmember calcium bicarbonate solution has a very depleted $\delta{ }^{13} \mathrm{C}_{\mathrm{DIC}}$ signature, dissolution of calcite from a relatively ${ }^{13} \mathrm{C}$ enriched rock endmember may result in carbon isotope enrichment of the reacted fluid. Based on the experimental results, the $\delta{ }^{13} \mathrm{C}_{\mathrm{DIC}}$ enrichments associated with the water-rock interaction, after correcting for $\mathrm{CO}_{2}$ degassing in the system, ranged from +13.0 to $+16.8 \%$ and +6.3 to $+8.2 \%$ in the low- and high-temperature experiments, respectively. These results suggest 
significant dissolution of calcite occurred as the calcium bicarbonate solution was exposed to the rock.

The oxygen isotope results from the low- and high-temperature static reactor experiments are represented in Figure 4. In both experimental systems, oxygen isotopes of the pre- and postreaction solutions remain nearly constant with approximate values of $-40 \%$. Using results from the high-temperature control tests, oxygen isotope enrichment associated $\mathrm{CO}_{2}$ degassing was calculated to enrich the $\delta^{18} \mathrm{O}$ of the solution by $+0.14 \%$. By applying a $\mathrm{CO}_{2}$ degassing correction factor of $-0.14 \%$ to the isotopic composition of the reacted solutions, the potential isotopic enrichments associated with water-rock interaction were quantified to range from 0.0 to $0.4 \%$. The observed oxygen isotopic shifts are within experimental error and are not considered representative of water-rock interaction in the experiments. The lack of measurable $\delta^{18} \mathrm{O}$ waterrock interaction in the experiments is likely associated with much higher abundance of oxygen atoms in solution compared to oxygen in rocks.

\section{Two Endmember Mixing Model}

The carbon isotope results suggest a larger degree of water-rock interaction in the lowtemperature experiments. However, variations in the endmember compositions of the experimental systems can amplify the apparent isotopic effect of the water-rock interaction when considering the magnitude of the isotopic shifts alone. To resolve this issue, the carbon isotope results from the low- and high-temperature static reactor experiments were applied to a two endmember isotope mixing model to determine the percent contribution of each endmember to the reacted solutions. The isotope mixing model can be described through the equation $\delta^{13} C_{\text {final }}=f_{1}\left(\delta^{13} C_{S 1}\right)+f_{2}\left(\delta^{13} C_{S 2}\right)$ where $\mathrm{f}_{1}$ and $\mathrm{f}_{2}$ are the percent contributions from each endmember 
and $\delta^{13} \mathrm{C}_{\mathrm{S} 1}$ and $\delta^{13} \mathrm{C}_{\mathrm{S} 2}$ are the isotopic compositions of each source. By applying this model, isotopic water-rock interactions from each experimental system can be compared.

Prior to applying the model to the experimental results, careful consideration was taken to account for changes in isotopic compositions associated with varying concentrations of different DIC species and fractionations associated with it. Throughout the experiments, the $\mathrm{pH}$ remained within the bicarbonate range, therefore, it is safe to presume that there was no major change in DIC composition. The shift in isotopic composition could be related to dissolution of isotopically enriched carbonates in the rock endmember and fractionation associated with the process. The temperature dependent carbon isotope fractionation factors $(\alpha)$ were calculated based on the equation $10^{3} \ln \alpha=a\left(10^{6} / T_{k}^{2}\right)+b\left(10^{3} / T_{k}\right)+c$ in which temperature $\left(\mathrm{T}_{\mathrm{k}}\right)$ is in degrees Kelvin and a, b, and c are constants (Deines et. al., 1974; and Kjartansdóttir, 2014). The resulting isotopic enrichments $\left(\varepsilon \approx 10^{3} \ln \alpha\right)$ calculated for calcite dissolution are -1.6 and $-1.5 \%$ at 90 and $144^{\circ} \mathrm{C}$, respectively. In order to account for $\mathrm{CO}_{2}$ degassing in the experiments, a $\delta^{13} \mathrm{C}_{\mathrm{DIC}}$ correction factor of $-1.4 \%$ was also calculated by averaging the $\delta^{13} \mathrm{C}_{\mathrm{DIC}}$ enrichment associated with $\mathrm{CO}_{2}$ degassing in the high-temperature control tests.

Results from the two-endmember isotope mixing model assist in the visualization and comparison of trends associated with water-rock interaction in the experiments (Figure 5). Model results indicate a 37.8 to $54.6 \% \delta^{13} \mathrm{C}$ contribution from the rock endmember to the reacted solution in the experiments with the remaining 45.4 to $62.2 \%$ sourcing back to the unreacted fluid endmember.

Variations in the endmember contribution to the reacted solutions do not correlate well with the sample depth or temperature. For example, the $1396 \mathrm{~m}$ high-temperature reaction demonstrates 
the largest influence of calcite dissolution while the $1396 \mathrm{~m}$ low-temperature reaction demonstrated the lowest influence of calcite dissolution. The observed variations are likely associated with the rock heterogeneity that resulted from the use of separately homogenized samples in each experiment. Although results from the low- and high-temperature $1358 \mathrm{~m}$ reactions are comparable and may be indicative of similar carbonate compositions in the samples, the potential for sample and fluid heterogeneities in the experimental systems make it difficult to ascertain any correlations with certainty.

\section{Geochemical Data}

With calcite mineral reactions anticipated to be the primary focus of this research, calcium and alkalinity concentrations as well as the $\mathrm{SI}_{\text {calcite }}$ were of particular interest in this study. Prior to the data analysis, it was thought that calcite dissolution would drive up the $\mathrm{SI}_{\text {calcite }}$ as $\mathrm{Ca}$ and alkalinity concentrations increased. However, the isotopic and geochemical results revealed a

more complex system. As discussed above, $\delta^{13} \mathrm{C}_{\mathrm{DIC}}$ analysis of the unreacted solution indicated a $\mathrm{CO}_{2}$ degassing trend through time. Not recognizing geochemical changes in the unreacted solution initially, the unreacted reservoir was not sampled for geochemical analysis prior to the low-temperature experiments. Due to the significant lag time prior to geochemical sampling of the unreacted solution, it is difficult to accurately assess changes in alkalinity, calcium, and SI $\mathrm{I}_{\text {calcite }}$ in the low-temperature system. As $\mathrm{CO}_{2}$ degassing occurred in the unreacted fluid reservoir through time, the calcium and alkalinity concentrations declined prior to geochemical sampling of the unreacted fluid. As a result, the measured calcium and alkalinity concentrations likely underestimate the initial fluid composition from the low-temperature experiments. Therefore, the decline in calcium concentrations observed in the low-temperature experiments may be larger than represented in the geochemical results (Figure 6). Similarly, the apparent 
increase in alkalinity in the low-temperature experiments may not be representative of the waterrock interactions in the experiments.

When considering only the high-temperature experiments, with accurate pre- and post-reaction calcium, alkalinity, and $\mathrm{SI}_{\text {calcite }}$ data, the calcium and alkalinity concentrations declined in the experiments and control tests with the exception of an anomalous increase in calcium in the 1396 m high-temperature reaction (Figure 6). Conversely, the $\mathrm{SI}_{\text {calcite }}$ increased in both the experiments and the control tests. The decline in calcium and alkalinity concentrations was more pronounced in the control tests than in the experiments while the increase in the $\mathrm{SI}_{\text {calcite }}$ was more prominent in the experiments (Table 4). These observations suggest that $\mathrm{CO}_{2}$ degassing and subsequent calcite precipitation occurred in the control tests under elevated temperature and pressure conditions, resulting in a decrease in calcium and alkalinity and an increase in the $\mathrm{SI}_{\text {calcite. }}$ While the effects of $\mathrm{CO}_{2}$ degassing are also prevalent in the experiments, water-rock interaction also played a significant role in the post-reaction fluid composition. In the experiments, early-stage calcite dissolution may have increased the calcium, alkalinity, and SI calcite prior to $\mathrm{CO}_{2}$ degassing and subsequent calcite precipitation thereby buffering the effects of $\mathrm{CO}_{2}$ degassing to some degree. However, silicate mineral reactions may have also had an impact on the calcium concentrations in the experiments through cation exchange with $\mathrm{Na}$ and $\mathrm{K}$.

Significant geochemical changes in the pre-and post-reaction samples from the experiments were also observed with respect to $\mathrm{Na}, \mathrm{K}$, and $\mathrm{Si}$. Based on the petrographic and geochemical data, the presence of these ions in the post reaction fluids are likely sourced to geochemical reactions with sodium-rich plagioclase $\left(\mathrm{NaAlSi}_{3} \mathrm{O}_{8}\right)$, muscovite $\left(\mathrm{KAl}_{2}\left(\mathrm{AlSi}_{2} \mathrm{O}_{10}\right)(\mathrm{OH})_{2}\right)$, and quartz $\left(\mathrm{SiO}_{2}\right)$. Although chlorite $\left((\mathrm{Mg}, \mathrm{Mn}, \mathrm{Al}, \mathrm{Fe})_{6}(\mathrm{Si}, \mathrm{Al})_{4} \mathrm{O}_{10}(\mathrm{OH})_{8}\right)$ is present in the rocks to varying degrees, 
the absence of significant $\mathrm{Al}, \mathrm{Mg}, \mathrm{Mn}$, and Fe in solution suggests that chlorite reactions are negligible in the experiments due to the slow dissolution rate of chlorite at elevated temperatures compared to quartz and feldspars (Smith and Carroll, 2014; and Palandri and Kharaka, 2004). The elevated $\mathrm{Na}$ and $\mathrm{K}$ concentrations in the post-reaction fluids are likely attributed to geochemical reactions with plagioclase and muscovite, respectively. With multiple silicate minerals present in the rock, elevated concentrations of $\mathrm{Si}$ are not as easily sourced but may be associated with plagioclase, muscovite, and/or quartz mineral reactions. These geochemical reactions appear to be quite complex as the mobilization and redistribution of ions can be affected by numerous processes such as dissolution, hydrolysis, precipitation, and ion exchange (Islam et al. 2002).

Within each experimental system, the $\mathrm{Si}, \mathrm{Na}$, and $\mathrm{K}$ concentrations appear to correlate with petrographic data from well $\mathrm{BCH}-03$. Post reaction fluids from the depths with high plagioclase, illite/muscovite, and quartz content demonstrate higher concentrations of $\mathrm{Na}, \mathrm{K}$, and $\mathrm{Si}$, respectively. However, there appears to be some variation from this trend with respect to the $\mathrm{Na}$ concentrations from the low-temperature experiments where the sample with the highest plagioclase content $(1358 \mathrm{~m})$ contains the lowest $\mathrm{Na}$ concentrations in the post-reaction fluids. This discrepancy may be associated with heterogeneity in the rock and/or complex geochemical reactions occurring in the system. The geochemical results also demonstrate a clear distinction between the low- and high-temperature experiments with respect to the $\mathrm{Na}, \mathrm{K}$, and $\mathrm{Si}$ concentrations. Higher concentrations of $\mathrm{Na}$ and $\mathrm{K}$ are present in the post-reaction fluid from the low-temperature experiments while higher Si concentrations are present in the post-reaction fluid from the high-temperature experiments (Figure 7). This might suggest that cation exchange and plagioclase and muscovite dissolution reactions may have been more prevalent in the low- 
temperature experiments, while quartz dissolution may be more prevalent in the hightemperature experiments. In-depth analysis of these complex geochemical reactions is outside the scope of this study.

\subsection{Conclusions}

Using cores from Brady's Field well BCH-03, three target depths (1358, 1396, 1459 m) were selected for high temperature and pressure geothermal laboratory experiments. A series of five experiments were conducted in April and December of 2014 in which powdered and crushed rock from each target depth was exposed to a calcium bicarbonate solution under elevated temperature $\left(90-144^{\circ} \mathrm{C}\right)$ and pressure (120 bar) conditions for 14-20 days. The isotopic composition of the fluid $\left(\delta^{13} \mathrm{C}_{\mathrm{DIC}}=-22.4\right.$ to $-39.8 \%$ and $\delta^{18} \mathrm{O}_{\mathrm{H} 2 \mathrm{O}}=-39.6$ to $-39.7 \%$ o $)$ and rock $\left(\delta^{13} \mathrm{C}_{\mathrm{DIC}}=-7.0\right.$ to $-9.3 \%$ and $\delta^{18} \mathrm{O}=-20.0$ to $-21.7 \%$ ) was analyzed prior to the experiments to ensure isotopically distinct endmember compositions. Due to the design of the pressure vessel systems, isotopic and geochemical sampling was limited to pre- and post-reaction samples. The resulting samples were analyzed to assess the feasibility of using carbon and oxygen isotopes in conjunction with geochemical data to monitor water-rock interactions in laboratory geothermal systems.

Water-rock interaction between the calcium bicarbonate solution and rock from well $\mathrm{BCH}-03$ would result in isotopic enrichments of $\delta^{13} \mathrm{C}_{\mathrm{DIC}}$ and $\delta^{18} \mathrm{O}_{\mathrm{H} 2 \mathrm{O}}$ as carbonate minerals dissolve. Throughout the experiments, $\delta^{18} \mathrm{O}_{\mathrm{H} 2 \mathrm{O}}$ of the post-reaction fluid remained constant ( -40\%o) while significant enrichments in $\delta^{13} \mathrm{C}_{\text {DIC }}$ were observed $(\varepsilon=+7.7$ to $+18.2 \%$ ). The discrepancy between the isotopic results suggests the lack of measurable $\delta^{18} \mathrm{O}$ shifts can be attributed to the abundance of oxygen in a solution that limited the impact of water-rock interaction on $\delta^{18} \mathrm{O}$. Complications emerged throughout the experiments due to $\mathrm{CO}_{2}$ degassing. Initial isotopic results 
revealed a $\mathrm{CO}_{2}$ degassing trend that led to an enrichment in the $\delta^{13} \mathrm{C}_{\text {DIC }}$ composition of the unreacted fluid through time. Recognizing this trend and the effects of temperature and pressure on $\mathrm{CO}_{2}$ solubility, control tests were conducted alongside the high-temperature experiments in an effort to constrain the effects of $\mathrm{CO}_{2}$ degassing. Results from the control tests revealed an average $\delta^{13} \mathrm{C}$ enrichment of $+1.4 \%$ associated with $\mathrm{CO}_{2}$ degassing in the system. Oxygen isotopes in the control tests remained constant suggesting that $\delta^{18} \mathrm{O}_{\mathrm{H} 2 \mathrm{O}}$ was unaffected by $\mathrm{CO}_{2}$ degassing due to the abundance of oxygen in solution. After accounting for $\delta^{13} \mathrm{C}_{\mathrm{DIC}}$ shifts associated $\mathrm{CO}_{2}$ degassing, post-reaction fluid enrichments associated with water-rock interaction were estimated to be +13.0 to $+16.8 \%$ and +6.3 to $+8.2 \%$ in the low- and high-temperature experiments, respectively. When considering only the magnitude of the isotopic shifts, relative differences in the endmember compositions of the experimental systems amplify the apparent isotopic effects of the water-rock interaction. For accurate comparison of the water-rock interactions in the low- and high-temperature experiments, a two-endmember isotope mixing model was applied to the carbon isotope results with careful consideration of isotopic fractionation. Model results indicated a 37.8 to $54.6 \%$ contribution of $\delta^{13} \mathrm{C}$ from the rock to the post-reaction fluid with the remaining 45.4 to $62.2 \%$ of $\delta^{13} \mathrm{C}$ sourcing back to the unreacted fluid endmember. The $\delta^{13} \mathrm{C}_{\text {DIC }}$ results suggest significant calcite dissolution occurs in all experiments; however, the results do not correlate well with sample depth or experimental temperature suggesting that fluid and rock heterogeneities impacted the degree of water-rock interaction.

The geochemical data support the isotopic results suggesting that early-stage calcite dissolution may have increased the calcium, alkalinity, and $\mathrm{SI}_{\text {calcite }}$ prior to significant $\mathrm{CO}_{2}$ degassing and subsequent calcite precipitation that resulted in a decline in calcium and alkalinity concentrations throughout the experiments. However, silicate mineral reactions may have also had an impact on 
the calcium concentrations in the experiments through cation exchange with $\mathrm{Na}$ and $\mathrm{K}$. Significant geochemical changes were also observed in the post-reaction samples from the experiments with respect to $\mathrm{Na}, \mathrm{K}$, and $\mathrm{Si}$. Based on the petrographic and geochemical data, the presence of these ions in the post reaction fluids are likely sourced to geochemical reactions with sodium-rich plagioclase, muscovite, and quartz. While the effects of calcite mineral reactions and $\mathrm{CO}_{2}$ degassing appear to dominate the isotopic and geochemical results, the geochemical data also suggests that complex silicate mineral reactions also played a significant role in the experiments.

\subsection{Acknowledgements}

This research was conducted in collaboration with the National Energy Technology Laboratory, Pennsylvania State University, and the University of Pittsburgh with funding provided by the DE-FOA-0000552 Funding Opportunity Announcement. We would like to thank Dr. Alexandra Hakala, Dr. Dustin Crandall, Karl Jarvis, James Fazio, and Jeff Martin for their invaluable assistance in the experimental design, setup, and execution. Lastly, we would like to acknowledge students and technicians in the West Virginia Stable Isotope Laboratory for their experimental and laboratory support. 


\section{0 - Using Carbon and Oxygen Isotopes to Monitor Water-Rock Interaction Under Simulated Geothermal Conditions in Experimental Flow-Through Systems}

\section{1 - Introduction}

As part of this thesis, a high temperature and pressure experimental flow-through system was developed and tested to assess the feasibility of using carbon and oxygen isotopes in conjunction with geochemical data to monitor water-rock interactions in a dynamic system under geothermal conditions. Using cores from Brady's Field Well BCH-03, investigations were conducted in the high-temperature flow-through system in which a calcium bicarbonate solution was pumped through fractured meta-volcanic rock cores from two target depths (1358 and $1396 \mathrm{~m})$. The flowthrough experiments were conducted for 14 days at $144^{\circ} \mathrm{C}$ and 103 bar pore-pressure. The flowthrough system enabled continuous flow of fluid through sub-cores from well BCH-03 under relevant geothermal conditions. Although temperatures in the field at the EGS target depths can be as high as $172-205^{\circ} \mathrm{C}$, laboratory temperatures were constrained by experimental capabilities. Using distinct isotopic endmembers, changes in the isotopic composition of the reacted fluid may be used to monitor water-rock interaction. As discussed below, numerous challenges emerged with the flow-through system that delayed and/or impacted the experiments. Despite the unique challenges and marginal experimental results, this work represents a large experimental effort that is critical to include in this thesis to provide lessons learned for others working with similar experimental systems.

\section{Development and Testing of the High-Temperature Flow-Through System}

The high-temperature flow-through system was constructed at the NETL-Morgantown using two Core Lab Instruments RCHR-Series stainless steel core holders wrapped in Protherm Industries 
PRT211002 Heating Jackets. The system consisted of two unreacted fluid reservoirs connected to separate Lab Alliance Series III High-Pressure Brine piston pumps for the supply fluid into two heated holders, each connected to a $500 \mathrm{ml}$ ISCO syringe pump for the application of pore pressure and collection of reacted fluid. In addition, a single $100 \mathrm{ml}$ ISCO syringe pump was used for the application of confining pressure to both core holders (Figures 8 and 9). A nitrogen supply line was used to fill the system prior experimentation and supply $\mathrm{N}_{2}$ gas to the unreacted reservoir headspace to limit atmospheric exposure of fluids throughout the experiments. All fluid transport lines connecting the pumps and core holders were composed of $0.318 \mathrm{~cm}$ OD stainless steel tubing. A Swagelok micro-metering valve was attached to the flow path between the core holder outlet and the receiving pumps to collect intermittent effluent fluid samples by use of a Luer Lock adapter and a Luer Lock gas tight syringe.

The Core Lab Instruments stainless steel core holders measure approximately $30.48 \mathrm{~cm}$ in length and $7.62 \mathrm{~cm}$ in inner diameter. Two threaded end caps seal the core holder with an interior 3.18 $\mathrm{cm}$ outer diameter tapered tube fitting (endcap seating flange) for the attachment of a $2.54 \mathrm{~cm}$ inner diameter flexible tubing to create a seal between the sample pathway and the outer confining fluid (Figure 10). Initially, a series of $2.54 \mathrm{~cm}$ diameter stainless steel spacers and end plugs were placed inside of the flexible tubing with $2.54 \mathrm{~cm}$ diameter rock cores to create the sample pathway. The purpose of the stainless-steel spacers and interior end plugs were to maintain the rigidity of the sample pathway and to attach $0.318 \mathrm{~cm}$ stainless steel tubing for fluid flow in and out of the system. The remaining volume in each core holder, outside of the isolated sample flow path, was filled with deionized water for the application of confining pressure.

Prior to the completion of the temperature-controlled system, a blank experiment was conducted on a simple system at ambient temperature to determine if significant fractionation was 
associated with flow through the system or the micro-metering valve position at which the samples were collected. Results from the initial blank suggested that no significant isotopic fractionation was associated with flow or valve position. Preliminary blank tests on the hightemperature flow-through system revealed significant challenges in the operation and successful execution of the experiments. Extensive blank testing was conducted to determine system operations and material interactions under elevated temperature and pressure conditions. The flexible tubing initially used to create the sample pathway was composed of EPDM rubber that was quickly found to interact isotopically with the experimental solutions under hightemperature conditions. Despite manufacturer stability ratings, water-rubber interaction caused major shifts in the carbon isotope ratio of the solutions. When tested with deionized water, water-rubber interaction continued to persist as evidenced by the incorporation of a significant amount of dissolved inorganic carbon (DIC) that declined in concentration throughout the experiment. Oxygen isotopes remained unaffected by the interaction with EPDM in all experiments, but are difficult to impact due to the abundance of oxygen in the water molecules.

Extensive research on highly resistant materials found Teflon and Viton to be the best polymers available for the experimental conditions. Thin walled $(0.127 \mathrm{~cm}) 2.54 \mathrm{~cm}$ inner diameter Teflon tubing with ideal chemical resistance was found to be too rigid to fit over the end cap seating flange and was employed as an interior sleeve in which all flow path components were placed (end plugs, cores, and spacers) (Figure 10). The Teflon inner sleeve was placed inside of $2.54 \mathrm{~cm}$ inner diameter flexible Viton tubing capable of stretching over the end cap seating flange to create a seal between the confining fluid and the sample pathway for the best possible chemical and temperature resistance. Initial tests indicated a minor amount of leakage from the confining fluid into the sample flow path as evidenced by the minor incorporation of DIC in the samples 
from deionized water blank tests. Analysis of confining fluid (deionized water) in contact with the Viton tubing indicated a small degree of carbon isotope interaction due to the incorporation of DIC. Therefore, it was crucial to continue using the Teflon inner sleeve in the experiments. In order to limit leakage into the sample flow path, Teflon tape was wrapped around edges of the inner sleeve before placement in the Viton outer sleeve. Careful monitoring of confining fluid volume in future experiments indicated that less than $1 \mathrm{ml}$ of confining fluid (Viton interacted deionized water) leaked into the flow path over the course of each experiment. With approximately $1400 \mathrm{ml}$ of total fluid flowing through the system in each experiment, the leakage was considered to be within experimental error with a percent contribution of less than $0.07 \%$.

The initial desire to run transmissivity measurements on the cores required the use of an epoxy to fill the edges of the fracture pathways to eliminate radial flow. Two types of epoxy were identified as being rated to withstand the experimental conditions (Dow Corning $730 \mathrm{FS}$ and Master Bond EP17HT). Experimental blanks containing each epoxy type were conducted placing cured epoxy in the flow path and on the edges of the inner Teflon sleeve in an attempt to further eliminate leakage. Results from epoxy blank tests indicated clear isotopic interaction with both epoxies resulting in the elimination of the epoxy and transmissivity measurements from the experiments. The resulting core holder setup was finalized as a Teflon inner sleeve filled with all flow pathway components and wrapped on the edges with Teflon tape before being placed inside of the Viton tubing for attachment to the end cap seating flanges. Deionized water continued to be used as the confining fluid to eliminate any further reaction with the Viton tubing and minor leakage was accepted as being within experimental error. An additional deionized water blank test was conducted on the system prior to starting the experiments in which no significant isotopic fractionation was observed in the finalized setup. 
Although the experimental setup was finalized, complications continued to arise in the flowthrough system due to the number of working parts. The most prevalent issues that occurred in the system were associated with pumps failures and improper seals. During several experiments, the piston pumps supplying fluid to the system became vapor locked due to the incorporation and propagation of air in the fluid supply lines likely associated with $\mathrm{CO}_{2}$ degassing. This issue could be resolved by temporarily decreasing pressure and priming the pump but resulted in a small volume of the fluid interacting with the rock for a number or hours before the issue was recognized and resolved. A pump failure also occurred in one receiving ISCO pump due to a shear key failure that caused a loss in confining pressure and resulted in a rupture of the Viton sleeve due to the unconfined pore pressure. For the most part, catastrophic experimental failures remained a result of improper seals in the system. Ruptures occurred when the Viton tubing was not completely seated around endcap seating flanges resulting in small leaks in the confining fluid that eventually led to a loss of confining pressure and rupturing the flow pathway. Fortunately, no catastrophic failures occurred during core experimentation and problems were limited to blank and control tests.

\section{2 - Methods}

The flow-through experiments that followed the experimental setup were successfully completed on two rock cores from Brady's Field Well BCH-03 (1358 and 1396 m). Each experiment was performed with the calcium bicarbonate solution used in the static reactions discussed above. Experiments were performed for two weeks prior to disassembly and post-experimental analysis. Calcium bicarbonate control tests were performed alongside each experiment for isotopic and geochemical comparison. In the control tests, three $2.54 \mathrm{~cm}$ OD stainless steel spacers and two end plugs were placed inside of a $20.32 \mathrm{~cm}$ section of thin walled $2.54 \mathrm{~cm}$ ID Teflon tubing 
(Figure 10). Each end of the Teflon tubing was then wrapped in Teflon tape and the end plugs were attached to $0.318 \mathrm{~cm}$ stainless steel tubing for fluid flow in and out of the sample flow pathway. Finally, the assembled inner sleeve was placed inside of a $23.813 \mathrm{~cm}$ section of 2.54 $\mathrm{cm}$ ID Viton tubing (Figure 10). Flow pathways for the core experiments were assembled using the methods described above with the exception of the replacement of one stainless steel spacer with a $2.54 \mathrm{~cm}$ rock core. All components of the system were cleaned extensively prior to each experiment.

In the assembly of the core holders, the assembled flow pathway was attached to the end cap seating flange on the upstream side of the system and tightened into the core holder (Figure 15). The downstream end cap was then tightened into the system, carefully sealing the end cap seating flange to the downstream section of the Viton Tubing. Once the sample flow pathway was isolated, deionized water was added to the confining space of each core holder for the application of confining pressure. While the confining space was filled, the flow pathway inlet and outlet lines were connected to the rest of the system making sure to check all connections for leaks. Using the Nitrogen supply line, the entire system was flushed prior to the introduction of fluid flow. Unreacted calcium bicarbonate solution was added to the pore pressure ISCO pumps to initially fill the flow path prior to the application of pore pressure. As pressure was increased, flow was introduced into the system at a rate of $0.07 \mathrm{ml} / \mathrm{min}$. The experiments were performed at $144^{\circ} \mathrm{C}, 103$ bar pore pressure, and 138 bar confining pressure. Once confining and pore pressures were maintained, the system was left overnight to achieve desired temperature conditions.

Samples were collected using the same methods in all experiments. Prior to experimental setup, initial samples from each experimental reservoir were collected for isotopic and geochemical 
analysis. After the experimental conditions were attained, effluent isotope samples were collected via the micro-metering sample valve bidaily for the initial two to three days of each experiment and daily thereafter. In most cases, effluent samples were not collected on weekends. At the midpoint of each experiment, the pore pressure ISCO pumps receiving reacted fluid from the system were emptied into a midpoint reservoir that was sampled for geochemical and isotopic analyses. Isotopic effluent samples continued to be collected daily for the remainder of the experiment. Prior to the experimental shutdown, final reservoirs were emptied from the receiving ISCO pumps and final geochemical and isotopic samples were collected.

Samples for isotopic analysis of fluids in the flow-through experiments were obtained using a Luer Lock tipped $1 \mathrm{ml}$ gas tight syringe. For the initial, midpoint, and final reservoirs, fluid was directly withdrawn from the reservoir using the gas tight syringe. All effluent samples were collected via the micro-metering sample valve, opening the valve slightly to limit pressure in the syringe. For isotopic analysis, $0.5 \mathrm{ml}$ of fluid was injected into each of the four $10 \mathrm{ml}$ sample vials; two flushed with helium for duplicate carbon isotope analysis and two flushed with $\mathrm{CO}_{2}$ in helium mix for duplicate oxygen isotope analysis. All sample vials were flushed using a ThermoQuest Finnigan GasBench II device coupled with a PAL autosampler system prior to sampling.

Isotopic analyses of fluid and rock samples were conducted using the PAL autosampler system and a Finnigan Delta Advantage IRMS. For carbon isotope analysis of DIC in solution, $0.1 \mathrm{ml}$ of phosphoric acid (80\%) was added to each sample collected in the helium flushed vials. The vials were then equilibrated at $25^{\circ} \mathrm{C}$ for 24 hours prior to analysis. Oxygen isotope analysis of fluid samples injected into the $\mathrm{CO}_{2}$ in helium mix flushed vials were equilibrated at $25^{\circ} \mathrm{C}$ for at least 24 hours prior to analysis. Carbon and Oxygen isotope analyses of solid samples were conducted 
prior to the experiments to understand the isotopic composition and heterogeneity of the solid endmembers. For each experiment, powdered rock was weighed to approximately $0.5 \mathrm{mg}$ and placed into unflushed $10 \mathrm{ml}$ gas bench vials prior to drying overnight at $50^{\circ} \mathrm{C}$ to eliminate residual water in the sample. Solid sample vials were then flushed with helium and acidified with $0.1 \mathrm{ml}$ of phosphoric acid (80\%), and equilibrated for 24 hours at $25^{\circ} \mathrm{C}$ prior to analysis.

Geochemical samples were collected and preserved in accordance with the NETL Pittsburgh Analytical Lab protocol for cations, anions, alkalinity, and $\mathrm{pH}$. Geochemical samples were analyzed at the NETL Pittsburgh Analytical Lab. Geochemical analyses were conducted via alkalinity titration, Ion Chromatography (IC), Inductively Coupled Plasma Mass Spectrometry (ICP-MS), and Inductively Coupled Plasma Optical Emission Spectroscopy (ICP-OES). All samples were measured for $\mathrm{pH}$ prior to sample collection and laboratory analysis. Geochemical characterization of the rock samples from these experiments was not conducted as part of this study.

\section{3 - Results and Discussion}

Extensive troubleshooting of the high temperature experimental flow-through system proved isotopic monitoring of water-rock interaction under elevated temperature and pressure conditions in a complex flow-through system to be a major challenge. Although oxygen isotopes of fluids are not significantly impacted by material interactions, they also remain resistant to water-rock interaction in systems with a high water to rock ratio and short residence time due to the abundance of oxygen in the water. In these systems, carbon isotopes of DIC were the major focus of water-rock interaction due to the limited concentration of carbon in solution. As is the case in water-rock interactions, material interactions that release carbon into solution have the ability to impart a significant shift in the carbon isotope ratio of DIC. Therefore, only highly inert 
materials can be used under elevated pressure and temperature conditions to observe carbon isotope water-rock interactions. Extensive material testing under elevated temperature $\left(144^{\circ} \mathrm{C}\right)$ and pressure (103 bar) conditions have proven Teflon and stainless steel to be the ideal materials for use. Although manufacturer specifications indicated that the Viton tubing was chemically resistant to $204^{\circ} \mathrm{C}$, experimental results indicate some degree of water-Viton interaction at $144^{\circ} \mathrm{C}$ with deionized water. Therefore, fluid-Viton contact should be avoided when studying carbon isotope water-rock interactions under elevated temperature and pressure conditions.

The high-temperature flow-through system was designed to emulate an enhanced geothermal system by flowing water into an artificially fractured core at a slow flow rate where the fluid is heated and allowed to interact with the rock before being pumped out of the system. In the experiments, unreacted fluid was continually supplied to the core. Given the temperature and residence time, calcite dissolution and precipitation were expected to be the mechanisms controlling isotopic shifts due to water-rock interaction. With a high water-rock ratio and short residence time, oxygen isotopes of the solution remained unaffected throughout the experiments and control test due to the abundance of oxygen in the water molecules; however, significant carbon isotope shifts were observed throughout the experiments (Table 4).

The carbon isotope results from the flow-through experiments are not as candid as expected due to significant isotopic shifts observed in the control tests run alongside each experiment (Table 4). Throughout the control tests, the $\delta^{13} \mathrm{C}_{\mathrm{DIC}}$ of the calcium bicarbonate solution exhibited an enrichment trend that is likely associated with $\mathrm{CO}_{2}$ degassing. As $\mathrm{CO}_{2}$ degasses in the system, the lighter carbon isotopes are preferentially taken out of solution resulting in an enrichment in $\delta^{13} \mathrm{C}_{\mathrm{DIC}}$. Analysis of the initial fluid, effluent samples and post-flow 
reservoirs indicate $\delta^{13} \mathrm{C}_{\mathrm{DIC}}$ enrichment through time, suggesting that $\mathrm{CO}_{2}$ degassing may be occurring in all portions of the system.

Throughout most of the core flow-through experiments, the $\delta^{13} \mathrm{C}_{\text {DIC }}$ of the solution exhibited more enrichment than observed in the blank experiments. The contrasting results suggest that minor $\delta^{13} \mathrm{C}_{\text {DIC }}$ enrichment may have occurred due to calcite dissolution in the experiments. The results from control tests performed alongside each experiment make it possible to estimate isotopic shifts associated with $\mathrm{CO}_{2}$ degassing and back calculate for the potential water-rock interaction. By comparing the isotopic shifts of $\delta^{13} \mathrm{C}_{\text {DIC }}$ in the control tests and flow-through experiments at each sampling point, an estimate of the $\delta^{13} \mathrm{C}_{\text {DIC }}$ composition related to water-rock interaction alone was calculated using the following equations in which $\Delta \delta^{13} \mathrm{C}_{\text {DIC }}$ (Experiment) is the isotopic shift observed at each sampling point during the experiments, $\Delta \delta^{13} \mathrm{C}_{\text {DIC }}$ (Control Test) is the isotopic shift observed at each sampling point during the control tests, $\Delta \delta^{13} \mathrm{C}_{\text {DIC }}$ (Water-Rock Interaction) is the isotopic shift associated with water-rock interaction at each sampling point in the experiments, and Corrected $\delta^{13} \mathrm{C}_{\mathrm{DIC}}$ is the corrected isotopic signature for each sample in the experiments that accounts for water-rock interaction alone (Table 4).

$$
\begin{gathered}
\Delta \delta^{13} \mathrm{C}_{\text {DIC (Experiment) }}=\operatorname{Initial} \delta^{13} \mathrm{C}_{\text {DIC (Experiment) }}-\text { Sample } \delta^{13} \mathrm{C}_{\text {DIC (Experiment })} \\
\Delta \delta^{13} \mathrm{C}_{\text {DIC }(\text { Control Test })}=\operatorname{Initial} \delta^{13} \mathrm{C}_{\text {DIC (Control Test })}-\text { Sample } \delta^{13} \mathrm{C}_{\text {DIC (Control Test })} \\
\Delta \delta^{13} \mathrm{C}_{\text {DIC (Water-Rock Interaction })}=\Delta \delta^{13} \mathrm{C}_{\text {DIC (Core Experiment) }}-\Delta \delta^{13} \mathrm{C}_{\text {DIC (Control Test })} \\
\text { Corrected } \delta^{13} \mathrm{C}_{\text {DIC }}=\text { Initial } \delta^{13} \mathrm{C}_{\text {DIC (Core Experiment) }}-\Delta \delta^{13} \mathrm{C}_{\text {DIC (Water-Rock Interaction })}
\end{gathered}
$$

Results from the corrected $\delta^{13} \mathrm{C}_{\text {DIC }}$ indicate similar trends in both core flow-through experiments (Figure 11). As the calcium bicarbonate solution contacts the rock, slight enrichments in $\delta^{13} \mathrm{C}_{\text {DIC }}$ 
were observed in the fluid in the fluid. In both experiments, the maximum extent of isotopic water-rock interaction associated with calcite dissolution $\left(+1.5\right.$ to $+2.2 \%$ o $\delta^{13} \mathrm{C}_{\text {DIC }}$ enrichment $)$ appears to occur within the first week of each experiment when the highest concentration of calcite is available in the core to dissolve (Figure 11). Greater $\delta^{13} \mathrm{C}_{\text {DIC }}$ enrichment is observed in the reaction with the $1358 \mathrm{~m}$ core, which may be associated with higher concentrations of calcite in the heterogeneous core. In the second week of the experiments, the isotopic shifts appear to stabilize in the $1358 \mathrm{~m}$ reaction and decline significantly in the $1396 \mathrm{~m}$ reaction. In the $1396 \mathrm{~m}$ experiment, there is an anomalous depletion in the $\delta^{13} \mathrm{C}_{\mathrm{DIC}}$ beyond the unreacted initial fluid composition during the second week of experimentation. This might be due to precipitation of ${ }^{13} \mathrm{C}$ rich calcite but could also be attributed to experimental error or carbon contamination from an alternate source in the complex system.

Changes in the $\delta^{13} \mathrm{C}_{\text {DIC }}$ fluid composition throughout the flow-through experiments indicate that some degree of water-rock interaction may have occurred in the system due to calcite dissolution. The initial enrichment of $\delta^{13} C_{\text {DIC }}$ suggests that water-rock interaction occurs rapidly upon water-rock contact under elevated temperature and pressure conditions. Declining $\delta^{13} \mathrm{C}_{\text {DIC }}$ in the second week of each test suggests that the amount of calcite available to dissolve in solution decreased and/or the ability of the solution to dissolve calcite decreased. Oxygen isotope results from initial, effluent, and reservoir samples remain unaltered throughout all the experiments and blanks (Figure 12). The lack of a trend in oxygen isotopes is likely due to the abundance oxygen in the water molecules resulting in a minimal impact of mineral dissolution.

The geochemical data provided in Table 5 support the isotopic results discussed above. With calcite mineral reactions anticipated to be the primary focus of this research, calcium and alkalinity concentrations as well as the $\mathrm{SI}_{\text {calcite }}$ were of particular interest to this study. Prior to 
the data analysis, it was thought that calcite dissolution would lead to increased concentrations of $\mathrm{Ca}$ and alkalinity and increased $\mathrm{SI}_{\text {calcite. However, the isotopic and geochemical results revealed a }}$ more complex system. In both the experiments and control tests, the calcium and alkalinity concentrations declined in most samples while the $\mathrm{SI}_{\text {calcite }}$ increased. The decline in calcium and alkalinity concentrations suggest that $\mathrm{CO}_{2}$ degassing and calcite precipitation occurred in the control tests under elevated temperature and pressure conditions, resulting in a decrease in

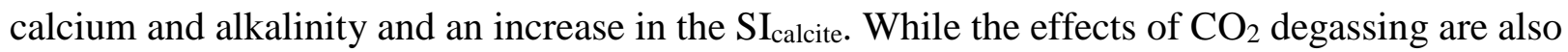
prevalent in the experiments, water-rock interaction may have also played a role in the postreaction fluid composition. However, unlike the geochemical results described in the static reactor experiments in the previous section, there do not appear to be a consistent distinction between the experiments and control tests with respect to calcium, alkalinity, and $\mathrm{SI}_{\text {calcite }}$.

Although outside the scope of this study, it is worth nothing that minor geochemical changes were also observed in the pre-and post-reaction samples from the experiments with respect to $\mathrm{Na}$ and $\mathrm{K}$ (Table 5). Although these geochemical changes are relatively small when compared to the static reactor experiments, they may also be sourced to geochemical reactions with sodium-rich plagioclase and muscovite. In contrast to the static reactor experiments, no Si was detected in the post-reaction reservoir samples from the flow-through experiments.

\section{4-Conclusions}

Numerous challenges were presented in the development and implementation of a high temperature and pressure flow-through system for monitoring water-rock interactions with carbon and oxygen isotopes. Under ideal conditions, similar systems may be employed successfully but complications quickly arise in complex systems when working with unstable solutions, reactive materials, and/or heterogeneous rocks. Material resistance and contaminant 
prevention are of the utmost importance when using stable isotopes to monitor water-rock interactions in complex, high-temperature systems. Experimental tests have shown Teflon and stainless steel appear to be the ideal materials for use in high-temperature experiments. Furthermore, careful experimental preparation and testing must be conducted prior to experimentation to ensure that all observations are representative of water-rock interactions.

The flow-through experiments conducted provide a continual supply of unreacted fluid to a hightemperature fractured core to assess water-rock interaction based on the resulting fluid composition. The advantage of the flow-through system when compared to the batch reactions is that it is more analogous to EGS. The observation of isotopic shifts associated with water-rock interaction is dependent on the use of an isotopically distinct and stable solution. The calcium bicarbonate solution used in the experiments was found to degas in the system, which presented challenges in the interpretation of isotopic shifts associated with the water-rock interaction. By conducting control tests alongside each experiment, changes in the $\delta^{13} \mathrm{C}_{\mathrm{DIC}}$ composition of the solution associated with $\mathrm{CO}_{2}$ degassing were quantified and isotopic shifts associated with waterrock interaction in the experiments were estimated.

Corrected $\delta^{13} \mathrm{C}_{\text {DIC }}$ results from the flow-through experiments indicate similar water-rock interaction trends in the experiments. As the calcium bicarbonate solution is exposed to the rock, calcite dissolution impacts the isotopic composition of DIC in the fluid. In both experiments, the maximum extent of isotopic water-rock interaction associated with calcite dissolution (1.5 to $2.2 \% \delta^{13} \mathrm{C}_{\mathrm{DIC}}$ enrichment) appears to occur within the first week of each experiment when the highest concentration of calcite is available in the core to dissolve. As the experiments progressed, the isotopic composition of the reacted fluid stabilized or decreased in $\delta^{13} \mathrm{C}_{\text {DIC }}$ as less calcite dissolution occurred. This stabilization or decrease in $\delta^{13} \mathrm{C}_{\text {DIC }}$ may be associated with the 
lower abundance of remaining calcite and/or an increase in the $\mathrm{SI}_{\text {calcite }}$ due to $\mathrm{CO}_{2}$ degassing. Oxygen isotope results from initial, effluent, and reservoir samples remain unaltered throughout all the experiments and blanks. The lack of a trend in oxygen isotopes is likely due to the abundance oxygen in the water molecules resulting in a minimal impact of mineral dissolution.

The geochemical data supports the isotopic results in that the calcium and alkalinity concentrations declined in most samples while the $\mathrm{SI}_{\text {calcite }}$ increased. The decline in calcium and alkalinity concentrations suggest that $\mathrm{CO}_{2}$ degassing and calcite precipitation occurred in the experiments and control tests under elevated temperature and pressure conditions, resulting in a decrease in calcium and alkalinity and an increase in the $\mathrm{SI}_{\text {calcite. While water-rock interaction }}$ may have also played a role in the post-reaction fluid composition, there do not appear to be consistent distinctions between the experiments and control tests with respect to calcium,

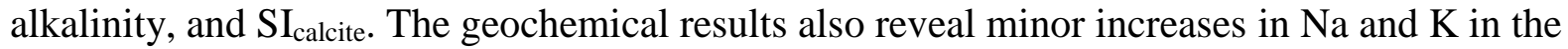
post-reaction fluid. Although these geochemical changes are relatively small, they may be sourced to geochemical reactions with sodium-rich plagioclase and muscovite. In contrast to the static reactor experiments, no Si was detected in the post-reaction reservoir samples from the flow-through experiments.

Although problems can arise when working with isotopically unstable solutions, isotopically heterogeneous solids and complex experimental systems with the potential for material interactions, successful implementation of these techniques can be applied to understand isotopic water-rock interaction in geologic systems. If applied to ideal systems and supported by isotopic and geochemical data, these systems may be highly successful in understanding changes in the fracture properties of rocks in high-temperature systems. 


\section{0 - Appendix A - Figures and Tables}

\section{1 - Figures}

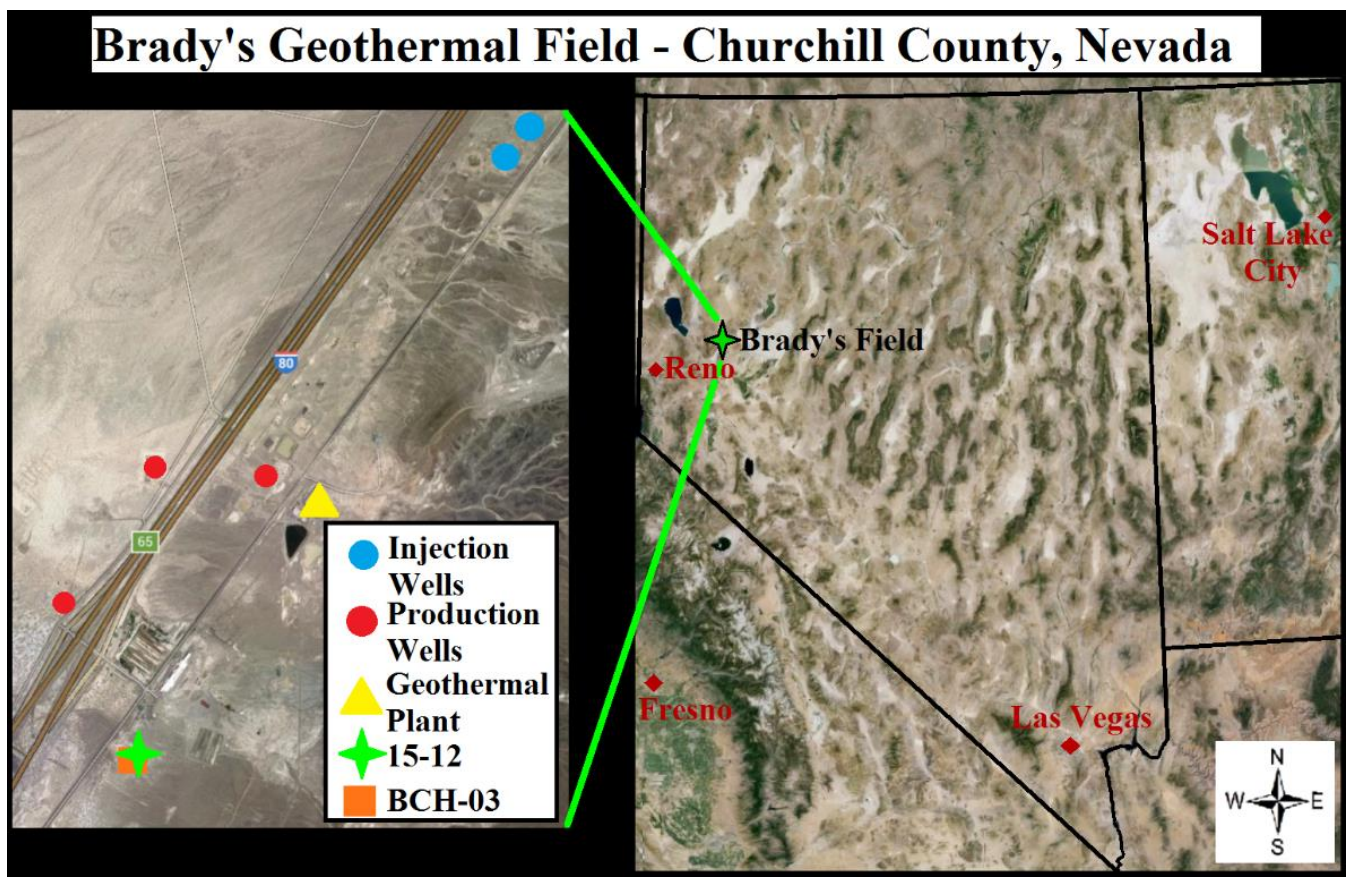

Figure 1: Map of Brady’s well field as modified from Google Earth
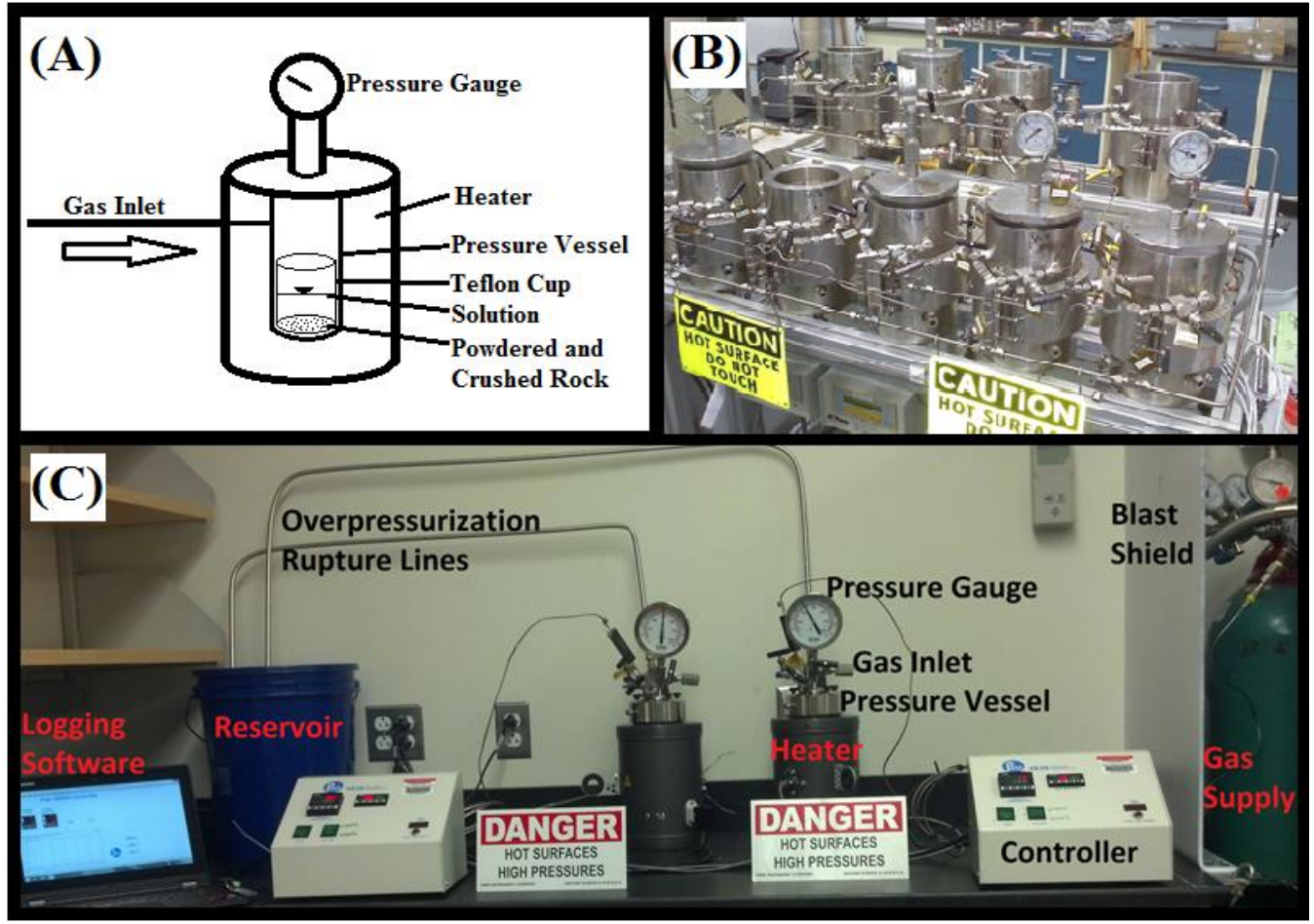

Figure 2: Depiction of the experimental pressure vessel systems showing (a) a simplified schematic of the experiments, (b) the low-temperature pressure vessel system, and (c) the high-temperature pressure vessel system 


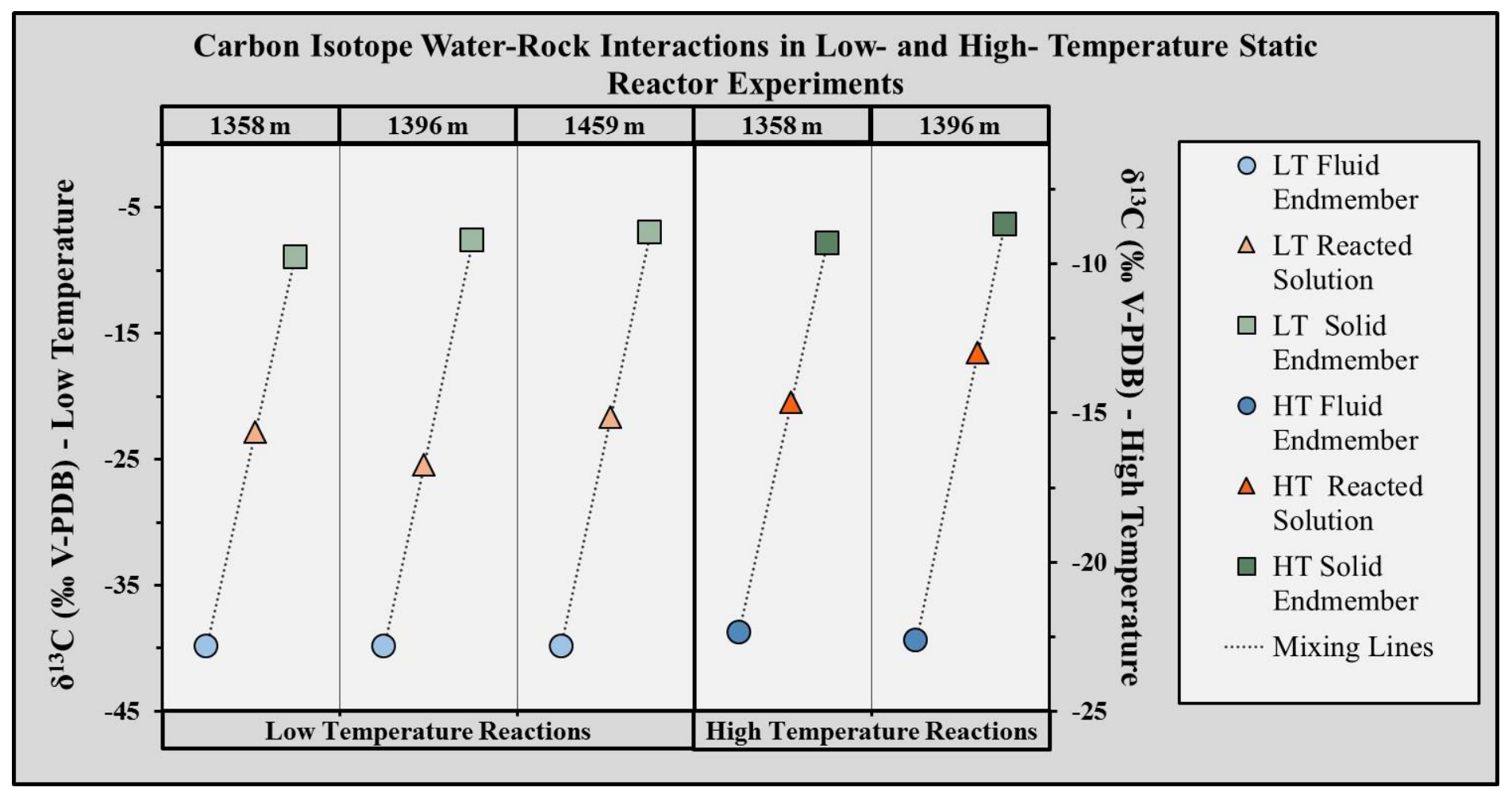

Figure 3: Carbon isotope shifts associated with water-rock interaction in the low-temperature (LT) and hightemperature (HT) static reactor experiments

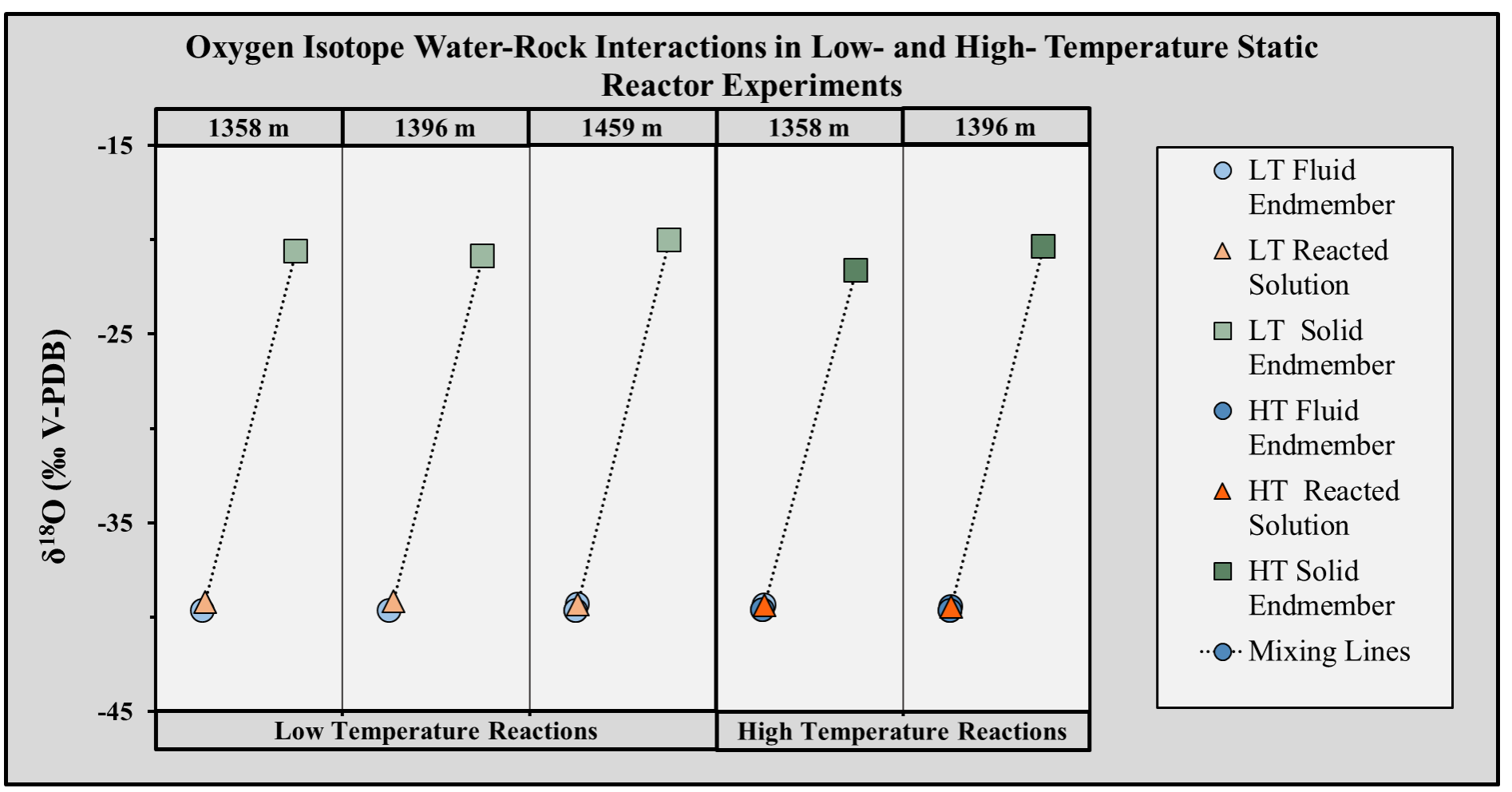

Figure 4: Oxygen isotopic shifts associated with water-rock interaction in the low-temperature (LT) and hightemperature (HT) static reactor experiments 


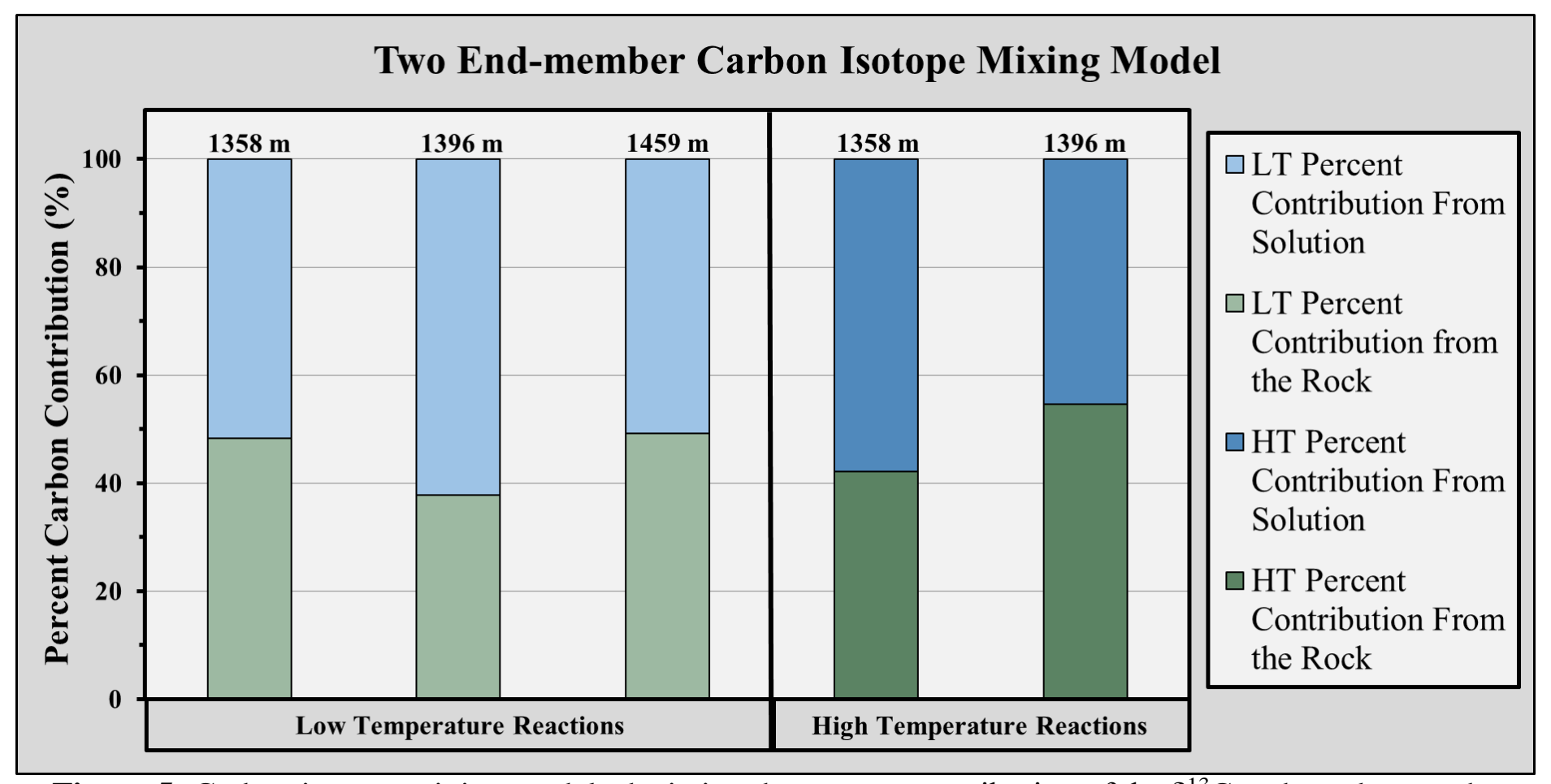

Figure 5: Carbon isotope mixing models depicting the percent contribution of the $\delta^{13} \mathrm{C}$ endmembers to the reacted fluid composition in the low-temperature (LT) and high-temperature (HT) static reactor experiments

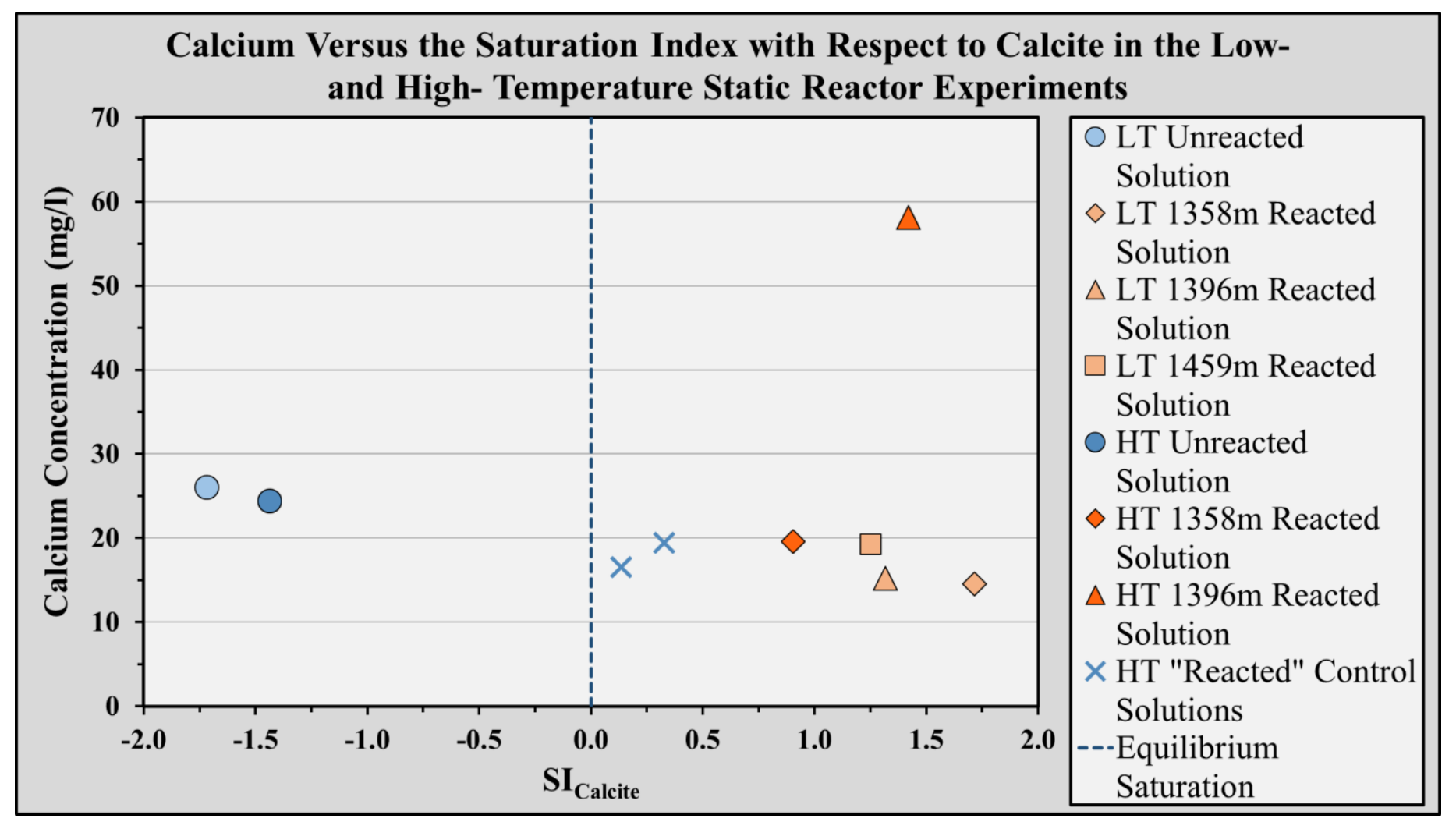

Figure 6: Calcium concentration versus the saturation index with respect to calcite in the low-temperature (LT) and high-temperature (HT) static reactor experiments 


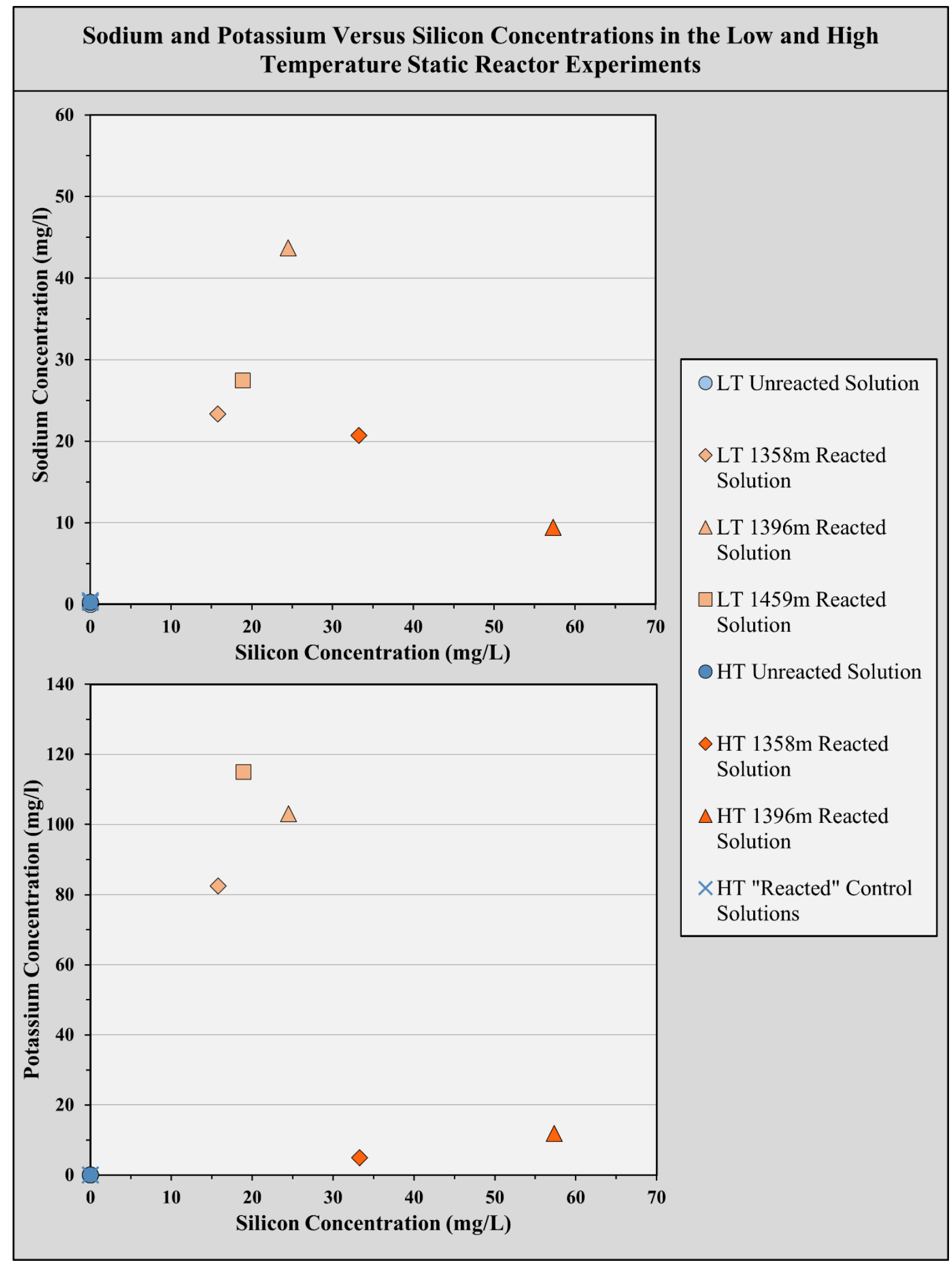

Figure 7: Sodium and potassium versus silicon concentrations in the low-temperature (LT) and hightemperature (HT) static reactor experiments 


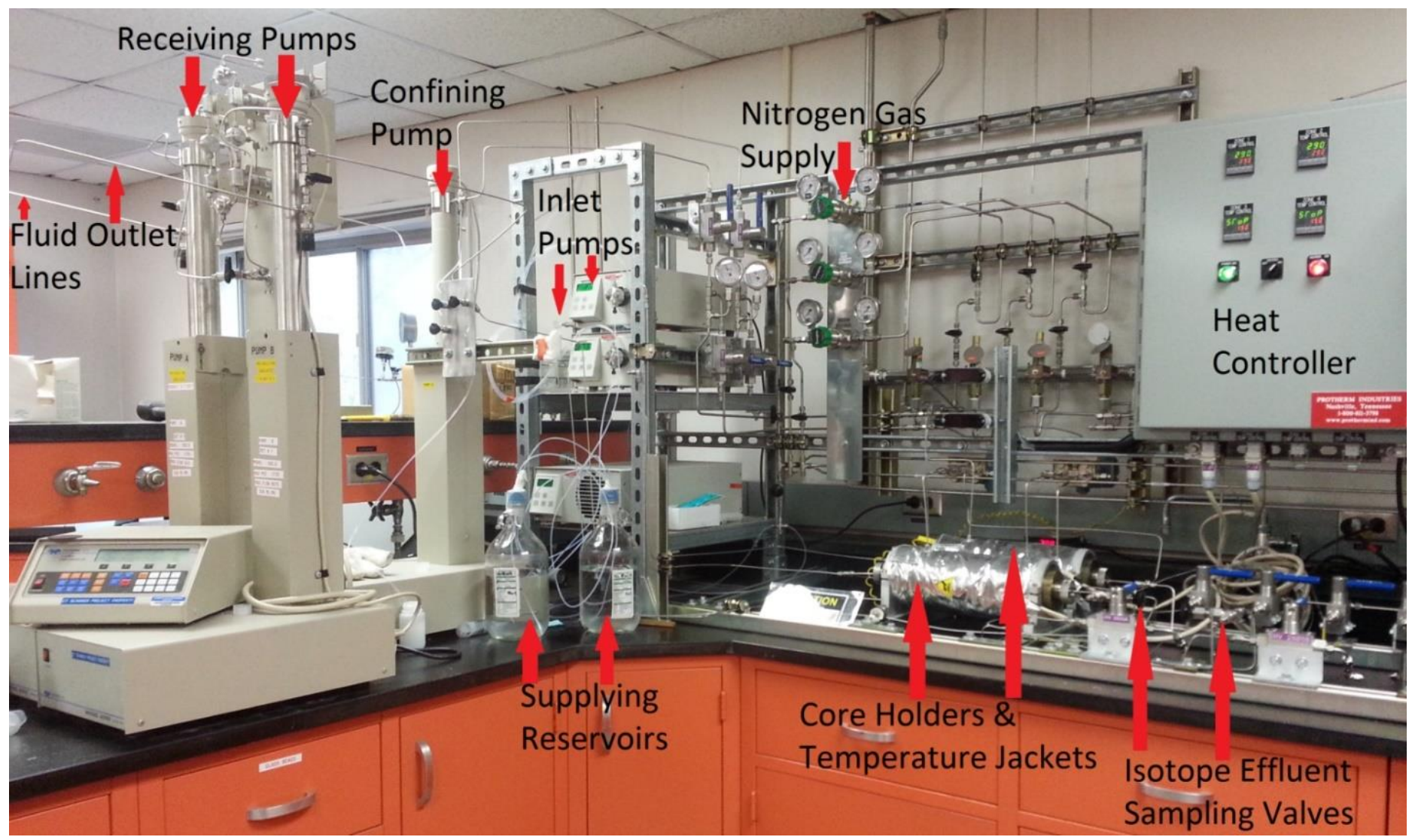

Figure 8: Labeled photograph of the temperature controlled flow-through system 


\section{Simplified Schematic of the Temperature Controlled Flow-Through System}

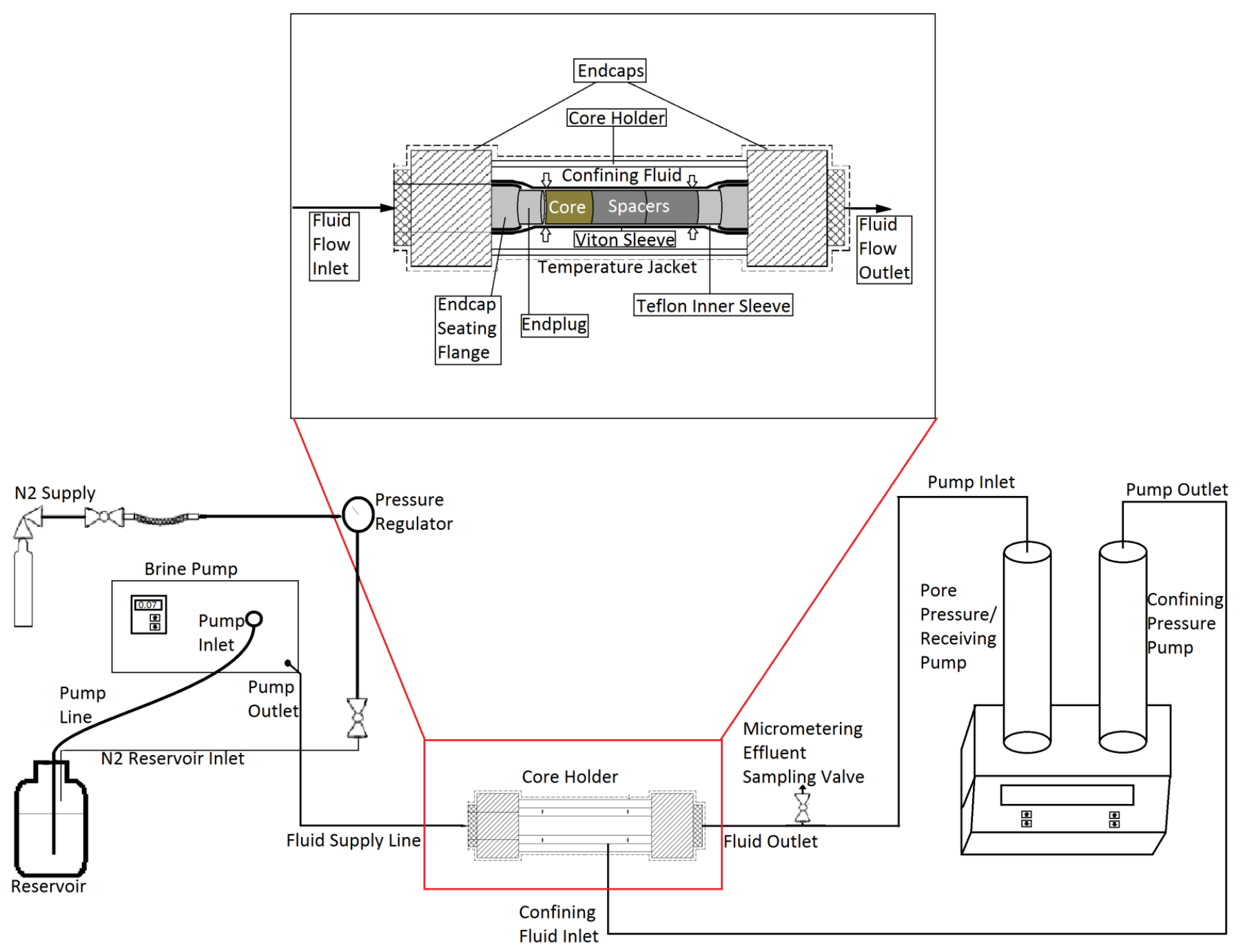

Figure 9: Simplified schematic of the temperature controlled flow-through system 

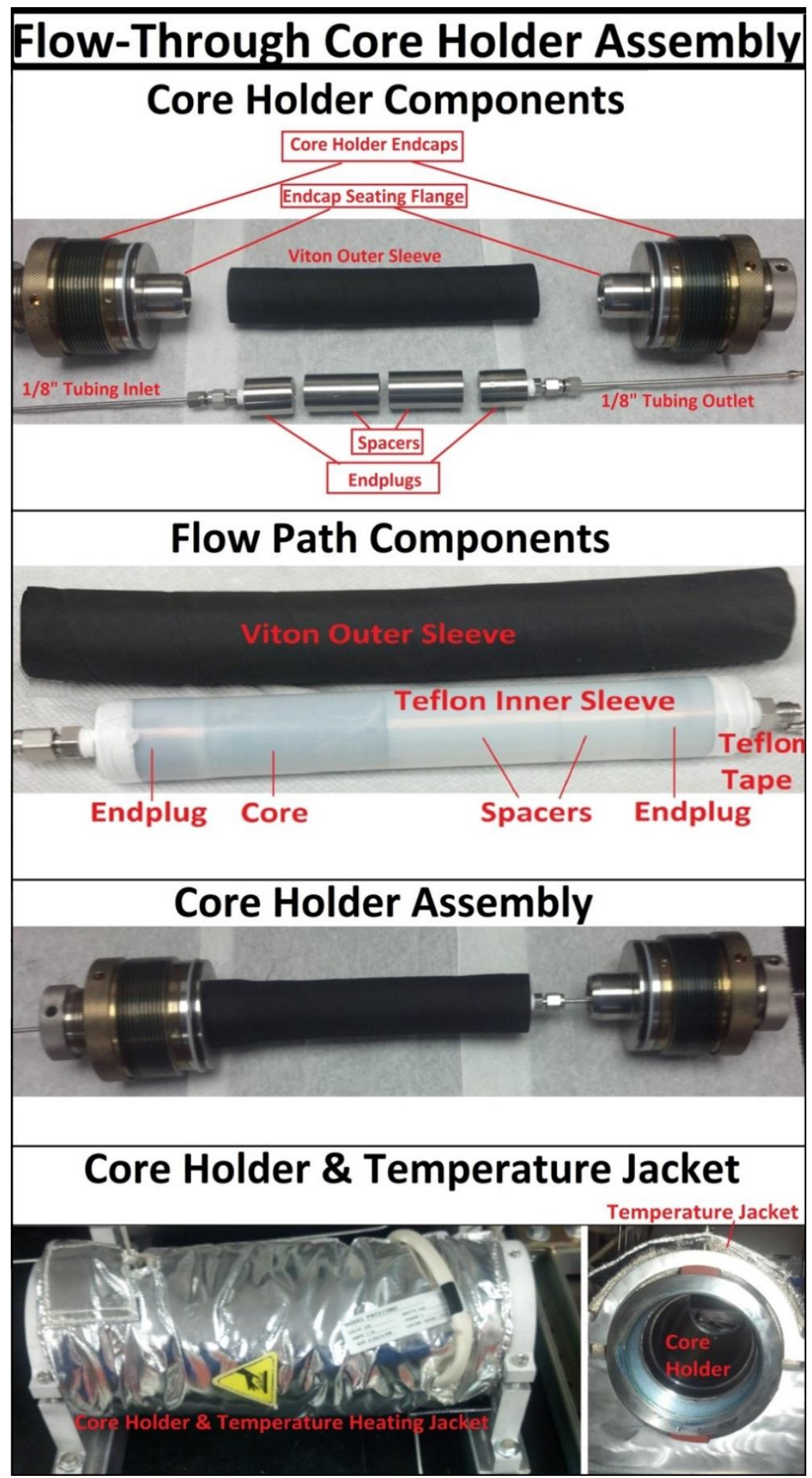

Figure 10: Labeled photographs showing the core holder components and assembly for the Morgantown-NETL flow-through experiments 


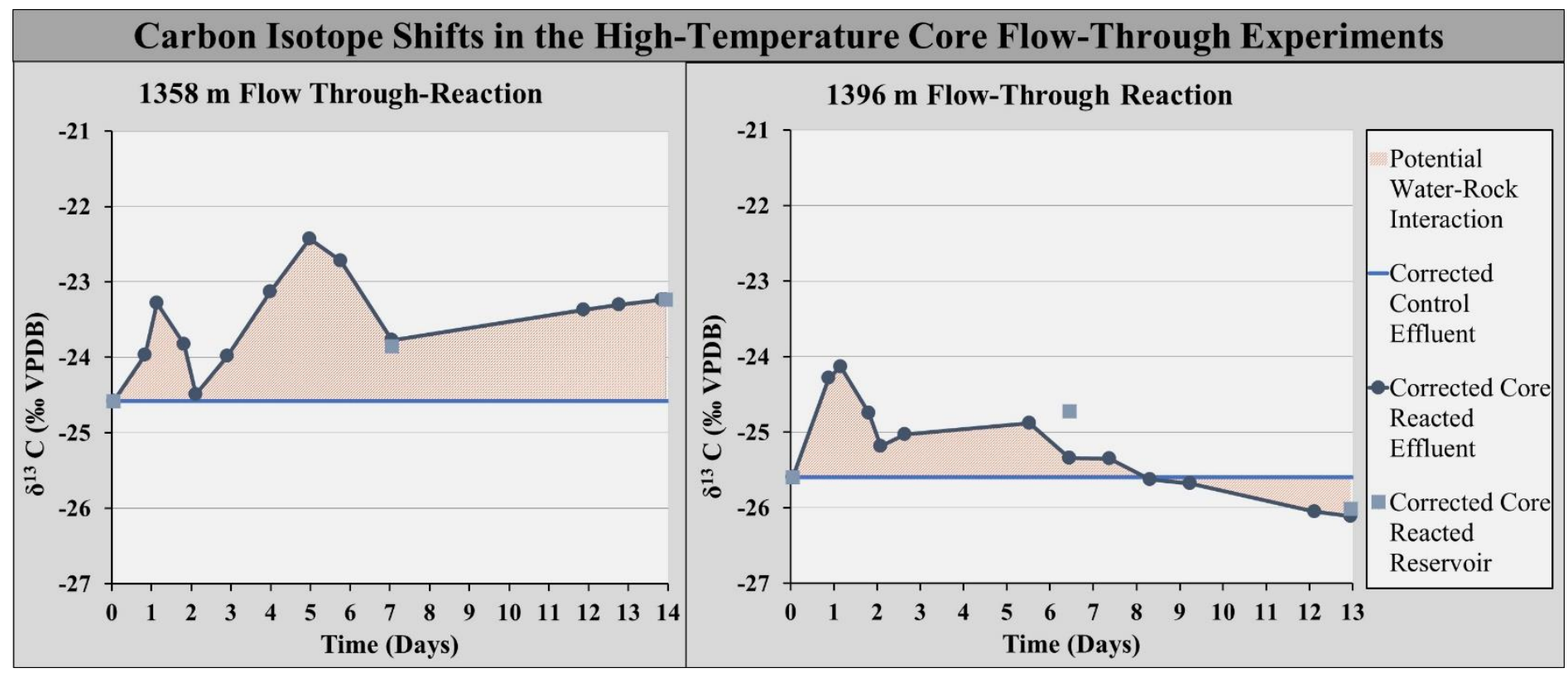

Figure 11: Carbon isotope shifts in the high-temperature core flow-through experiments corrected for $\mathrm{CO}_{2}$ degassing to show the extent of possible water-rock interaction

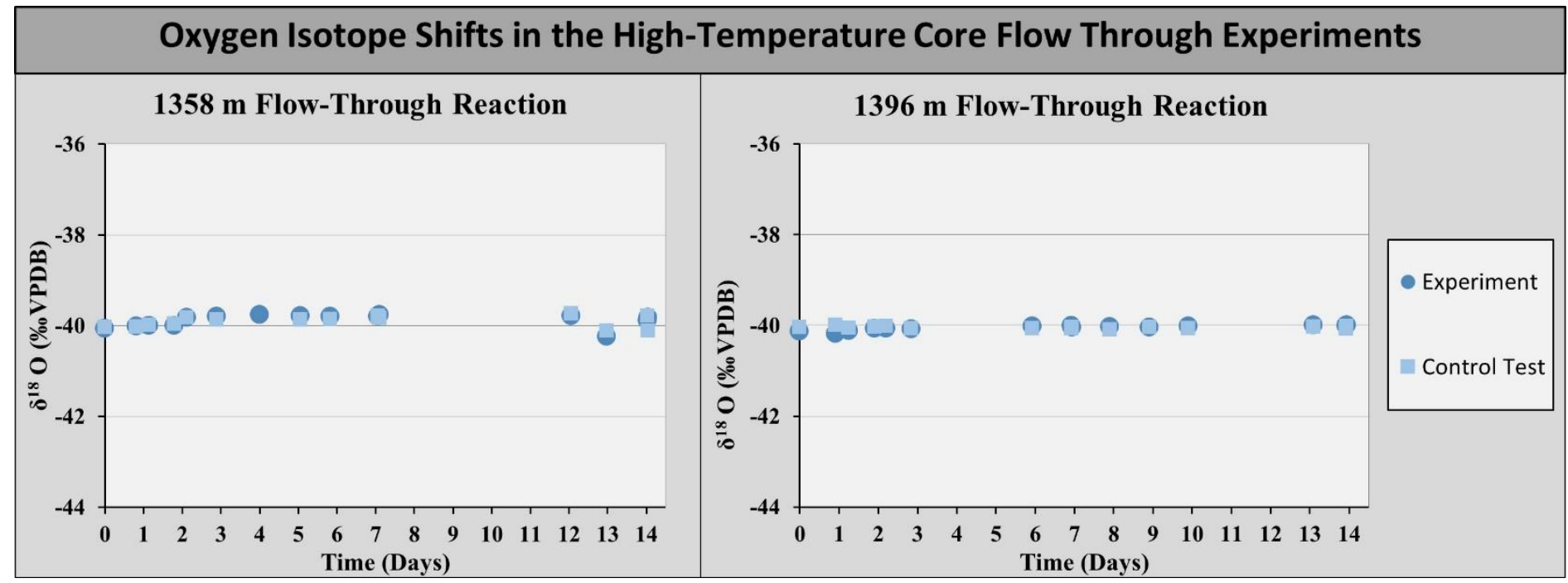

Figure 12: Oxygen isotope fluid composition in the high-temperature core flow-through experiments 


\begin{tabular}{|c|c|c|c|}
\hline \multicolumn{4}{|c|}{$\begin{array}{l}\text { Isotopic Results from the Low- and High- Temperature } \\
\text { Static Reactor Experiments }\end{array}$} \\
\hline Experiment & Sample Description & $\begin{array}{c}\delta^{13} \mathrm{C} \\
(\% \circ \mathrm{V}-\mathrm{PDB})\end{array}$ & $\begin{array}{c}\delta^{18} \mathrm{O} \\
(\% \circ \mathrm{V}-\mathrm{PDB})\end{array}$ \\
\hline \multirow{3}{*}{$\begin{array}{l}\text { Low Temperature: } \\
1358 \text { m Reaction }\end{array}$} & Unreacted $\mathrm{CaHCO}_{3}$ Solution & -39.82 & -39.68 \\
\hline & Reacted $\mathrm{CaHCO}_{3}$ Solution & -22.81 & -39.18 \\
\hline & Unreacted 1358 m Rock & -8.91 & -20.64 \\
\hline \multirow{3}{*}{$\begin{array}{l}\text { Low Temperature: } \\
\text { 1396m Reaction }\end{array}$} & Unreacted $\mathrm{CaHCO}_{3}$ Solution & -39.82 & -39.68 \\
\hline & Reacted $\mathrm{CaHCO}_{3}$ Solution & -25.42 & -39.15 \\
\hline & Unreacted 1396 m Rock & -7.61 & -20.88 \\
\hline \multirow{3}{*}{$\begin{array}{l}\text { Low Temperature: } \\
\text { 1459m Reaction }\end{array}$} & Unreacted $\mathrm{CaHCO}_{3}$ Solution & -39.82 & -39.68 \\
\hline & Reacted $\mathrm{CaHCO}_{3}$ Solution & -21.65 & -39.32 \\
\hline & Unreacted 1459 m Rock & -7.00 & -20.03 \\
\hline \multirow{3}{*}{$\begin{array}{l}\text { High Temperature: } \\
\text { 1358m Reaction }\end{array}$} & Unreacted $\mathrm{CaHCO}_{3}$ Solution & -22.37 & -39.62 \\
\hline & Reacted $\mathrm{CaHCO}_{3}$ Solution & -14.65 & -39.36 \\
\hline & Unreacted 1358 m Rock & -9.32 & -21.66 \\
\hline \multirow{3}{*}{$\begin{array}{l}\text { High Temperature: } \\
\text { 1396m Reaction }\end{array}$} & Unreacted $\mathrm{CaHCO}_{3}$ Solution & -22.63 & -39.64 \\
\hline & Reacted $\mathrm{CaHCO}_{3}$ Solution & -12.99 & -39.47 \\
\hline & Unreacted 1396 m Rock & -8.69 & -20.37 \\
\hline \multirow{2}{*}{$\begin{array}{c}\text { High Temperature: } \\
\text { Control } 1\end{array}$} & Initial $\mathrm{CaHCO}_{3}$ Solution & -22.37 & -39.62 \\
\hline & Final $\mathrm{CaHCO}_{3}$ Solution & -20.89 & -39.44 \\
\hline \multirow{2}{*}{$\begin{array}{l}\text { High Temperature: } \\
\text { Control } 2\end{array}$} & Initial $\mathrm{CaHCO}_{3}$ Solution & -22.63 & -39.64 \\
\hline & Final $\mathrm{CaHCO}_{3}$ Solution & -21.38 & -39.55 \\
\hline
\end{tabular}

Table 1: Pre- and post-reaction isotopic compositions of solution and rock from the low- and high-temperature static reactor experiments 


\begin{tabular}{|c|c|c|}
\hline $\begin{array}{c}\text { Two Endmember Isotope Mixing Model Results from the Low- } \\
\text { and High- Temperature Static Reactor Experiments }\end{array}$ \\
\hline Reaction & $\begin{array}{c}\boldsymbol{\delta}^{\mathbf{1 3}} \text { C Percent } \\
\text { Contribution from } \\
\text { Fluid Endmember to } \\
\text { Reacted Solution }\end{array}$ & $\begin{array}{c}\boldsymbol{\delta}^{\mathbf{1 3}} \text { C Percent } \\
\text { Contribution from } \\
\text { Solid Endmember to } \\
\text { Reacted Solution }\end{array}$ \\
\hline $\begin{array}{c}\text { Low Temperature: } \\
\text { 1358 m Reaction }\end{array}$ & 51.6 & 48.4 \\
\hline $\begin{array}{c}\text { Low Temperature: } \\
\text { 1396m Reaction }\end{array}$ & 62.2 & 37.8 \\
\hline $\begin{array}{c}\text { Low Temperature: } \\
\text { 1459m Reaction }\end{array}$ & 50.9 & 49.1 \\
\hline $\begin{array}{c}\text { High Temperature: } \\
\text { 1358m Reaction }\end{array}$ & 57.8 & 42.2 \\
\hline $\begin{array}{c}\text { High Temperature: } \\
\text { 1396m Reaction }\end{array}$ & 45.4 & 54.6 \\
\hline
\end{tabular}

Table 2: Results from the two-endmember carbon isotope mixing model using data from the low- and hightemperature static reactor experiments

\begin{tabular}{|c|c|c|c|c|c|c|c|c|}
\hline \multicolumn{9}{|c|}{ Geochemical Results from the Low- and High- Temperature Static Reactor Experiments } \\
\hline Experiment & Description & $\begin{array}{l}\text { Sampling } \\
\text { Date }\end{array}$ & $\begin{array}{c}\text { Alkalinity } \\
(\mathrm{mg} / \mathrm{L} \\
\left.\mathrm{CaCO}_{3}\right)\end{array}$ & $\underset{(m g / L)}{\mathrm{Si}}$ & $\begin{array}{c}\mathrm{Na} \\
(\mathbf{m g} / \mathrm{L})\end{array}$ & $\begin{array}{c}\mathrm{K} \\
(\mathrm{mg} / \mathrm{L})\end{array}$ & $\begin{array}{c}\mathrm{Ca} \\
(\mathrm{mg} / \mathrm{L})\end{array}$ & SI $_{\text {Calcite }}$ \\
\hline \multirow{4}{*}{$\begin{array}{l}\text { Low Temperature } \\
\text { Experiments }\end{array}$} & Unreacted $\mathrm{Ca}-\mathrm{HCO}_{3}$ Solution & $11 / 4 / 14$ & 71.2 & 0 & 0 & 0 & 26.0 & -1.7 \\
\hline & $1358 \mathrm{~m}$ Reacted Ca- $\mathrm{HCO}_{3}$ Solution & $5 / 8 / 14$ & 369.0 & 15.8 & 23.4 & 82.5 & 14.5 & 1.7 \\
\hline & $1396 \mathrm{~m}$ Reacted $\mathrm{Ca}-\mathrm{HCO}_{3}$ Solution & $5 / 8 / 14$ & 219.0 & 24.5 & 43.7 & 103.1 & 15.2 & 1.3 \\
\hline & $1459 \mathrm{~m}$ Reacted Ca- $\mathrm{HCO}_{3}$ Solution & $5 / 8 / 14$ & 205.0 & 18.9 & 27.5 & 115.0 & 19.2 & 1.3 \\
\hline \multirow{3}{*}{$\begin{array}{l}\text { High Temperature } \\
\text { Experiments }\end{array}$} & Unreacted $\mathrm{Ca}-\mathrm{HCO}_{3}$ Solution & $12 / 10 / 14$ & 96.0 & 0 & 0.3 & 0 & 24.4 & -1.4 \\
\hline & $1358 \mathrm{~m}$ Reacted $\mathrm{Ca}-\mathrm{HCO}_{3}$ Solution & $1 / 14 / 15$ & 78.5 & 33.2 & 20.7 & 4.9 & 19.6 & 0.9 \\
\hline & 1396 m Reacted Ca- $\mathrm{HCO}_{3}$ Solution & $12 / 29 / 14$ & 83.0 & 57.3 & 9.4 & 11.9 & 58.1 & 1.4 \\
\hline \multirow{3}{*}{$\begin{array}{l}\text { High Temperature } \\
\text { Control Tests }\end{array}$} & Unreacted Ca- $\mathrm{HCO}_{3}$ Solution & $12 / 10 / 14$ & 96.0 & 0 & 0.3 & 0 & 24.4 & -1.4 \\
\hline & Final Ca- $\mathrm{HCO}_{3}$ Solution & $1 / 14 / 15$ & 44.0 & 0 & 0.3 & 0 & 16.6 & 0.1 \\
\hline & Final Ca- $\mathrm{HCO}_{3}$ Solution & $12 / 29 / 14$ & 65.0 & 0 & 0.5 & 0 & 19.4 & 0.3 \\
\hline
\end{tabular}

Table 3: Geochemical results from the low- and high--temperature static reactor experiments. Values reported as " $O$ " indicate concentrations below the detection limit. 


\begin{tabular}{|c|c|c|c|c|c|c|c|}
\hline \multicolumn{8}{|c|}{$\begin{array}{c}\text { Isotopic Results from the High-Temperature Flow-Through Experiments and } \\
\text { Control Tests }\end{array}$} \\
\hline Experiment & Description & $\begin{array}{l}\text { Sample } \\
\text { Time } \\
\text { (Days) }\end{array}$ & $\begin{array}{l}\text { Control Test } \\
\quad \delta^{13} \mathrm{C} \\
(\% \text { V-PDB })\end{array}$ & $\begin{array}{l}\text { Experiment } \\
\qquad \delta^{13} \mathrm{C} \\
(\% \text { V-PDB })\end{array}$ & $\begin{array}{l}\text { Corrected } \\
\text { Experiment } \\
\delta^{13} \mathrm{C} \\
(\% \mathrm{~V}-\mathrm{PDB})\end{array}$ & $\begin{array}{l}\text { Control Test } \\
\quad \delta^{18} \mathrm{O} \\
(\% \text { V-PDB) }\end{array}$ & $\begin{array}{c}\text { Experiment } \\
\delta^{18} \mathrm{O} \\
(\% \text { V-PDB) }\end{array}$ \\
\hline \multirow{15}{*}{$\begin{array}{c}1358 \text { m Flow- } \\
\text { Through } \\
\text { Experiment and } \\
\text { Control Test }\end{array}$} & Unreacted Reservoir & 0.0 & -24.8 & -24.6 & -24.6 & -40.0 & -40.1 \\
\hline & Effluent 1 & 0.8 & -23.3 & -22.5 & -24.0 & -40.0 & -40.0 \\
\hline & Effluent 2 & 1.1 & -24.2 & -22.8 & -23.3 & -40.0 & -40.0 \\
\hline & Effluent 3 & 1.8 & -24.1 & -23.2 & -23.8 & -40.0 & -40.0 \\
\hline & Effluent 4 & 2.1 & -23.1 & -22.8 & -24.5 & -39.8 & -39.8 \\
\hline & Effluent 5 & 2.9 & -23.7 & -22.9 & -24.0 & -39.9 & -39.8 \\
\hline & Effluent 6 & 4.0 & -24.3 & -22.6 & -23.1 & & -39.8 \\
\hline & Effluent 7 & 5.1 & -24.9 & -22.6 & -22.4 & -39.9 & -39.8 \\
\hline & Effluent 8 & 5.8 & -24.6 & -22.5 & -22.7 & -39.9 & -39.8 \\
\hline & Effluent 9 & 7.1 & -23.5 & -22.5 & -23.8 & -39.8 & -39.8 \\
\hline & Midpoint Reservoir & 7.1 & -22.2 & -21.3 & -23.9 & -39.8 & -39.8 \\
\hline & Effluent 10 & 12.1 & -24.1 & -22.7 & -23.4 & -39.7 & -39.8 \\
\hline & Effluent 11 & 13.0 & -24.3 & -22.7 & -23.3 & -40.1 & -40.2 \\
\hline & Effluent 12 & 14.0 & -24.6 & -23.0 & -23.2 & -39.8 & -39.9 \\
\hline & Final Reservoir & 14.0 & -23.3 & -21.8 & -23.2 & -40.1 & -39.8 \\
\hline \multirow{15}{*}{$\begin{array}{c}1396 \text { m Flow- } \\
\text { Through } \\
\text { Experiment and } \\
\text { Control Test }\end{array}$} & Unreacted Reservoir & 0.0 & -25.4 & -25.6 & -25.6 & -40.0 & -40.1 \\
\hline & Effluent 1 & 0.9 & -23.9 & -22.8 & -24.3 & -40.0 & -40.2 \\
\hline & Effluent 2 & 1.3 & -23.9 & -22.6 & -24.1 & -40.1 & -40.1 \\
\hline & Effluent 3 & 1.9 & -23.9 & -23.2 & -24.7 & -40.0 & -40.1 \\
\hline & Effluent 4 & 2.2 & -23.6 & -23.4 & -25.2 & -40.0 & -40.1 \\
\hline & Effluent 5 & 2.8 & -23.8 & -23.4 & -25.0 & -40.1 & -40.1 \\
\hline & Effluent 6 & 5.9 & -23.8 & -23.2 & -24.9 & -40.1 & -40.0 \\
\hline & $\begin{array}{l}\text { Effluent } 7 \\
\end{array}$ & 6.9 & -23.3 & -23.2 & -25.3 & -40.1 & -40.0 \\
\hline & Midpoint Reservoir & 6.9 & -22.5 & -21.8 & -24.7 & -40.0 & -40.0 \\
\hline & Effluent 8 & 7.9 & -23.0 & -23.0 & -25.3 & -40.1 & -40.0 \\
\hline & Effluent 9 & 8.9 & -22.7 & -23.0 & -25.6 & -40.0 & -40.0 \\
\hline & Effluent 10 & 9.9 & -22.7 & -22.9 & -25.7 & -40.1 & -40.0 \\
\hline & Effluent 11 & 13.1 & -22.7 & -23.4 & -26.1 & -40.0 & -40.0 \\
\hline & Effluent 12 & 13.9 & -22.6 & -23.3 & -26.1 & -40.1 & -40.0 \\
\hline & Final Reservoir & 13.9 & -21.3 & -21.9 & -26.0 & -40.0 & -40.0 \\
\hline
\end{tabular}

Table 4: Isotopic results from the high-temperature flow-through experiments and control tests 


\begin{tabular}{|c|c|c|c|c|c|c|c|}
\hline \multicolumn{8}{|c|}{$\begin{array}{c}\text { Geochemical Results from the High-Temperature Flow-Through } \\
\text { Experiments and Control Tests }\end{array}$} \\
\hline Experiment & Description & $\begin{array}{c}\text { Alkalinity } \\
(\mathrm{mg} / \mathrm{L} \text { as } \\
\left.\mathrm{CaCO}_{3}\right)\end{array}$ & $\begin{array}{c}\text { Ca } \\
(\mathrm{mg} / \mathrm{L})\end{array}$ & $\begin{array}{c}\mathrm{Na} \\
(\mathrm{mg} / \mathrm{L})\end{array}$ & K (mg/L) & $\mathrm{Si}(\mathrm{mg} / \mathrm{L})$ & $\mathbf{S I}_{\text {Calcite }}$ \\
\hline \multirow{3}{*}{$\begin{array}{l}1358 \text { m Flow-Through } \\
\text { Experiment }\end{array}$} & Unreacted Reservoir & 73.8 & 26.5 & 0 & 0.1 & 0 & -1.3 \\
\hline & Midpoint Reservoir & 66.9 & 18.5 & 4.6 & 1.6 & 0 & 0.7 \\
\hline & Final Reservoir & 79.3 & 18.5 & 1.9 & 0.8 & 0 & 0.3 \\
\hline \multirow{3}{*}{ Control Test 1} & Unreacted Reservoir & 70.6 & 25.3 & 0 & 0 & 0 & -1.4 \\
\hline & Midpoint Reservoir & 52.5 & 19.6 & 2.3 & 0.1 & 0 & 0.4 \\
\hline & Final Reservoir & 77.1 & 21.9 & 2.0 & 0.1 & 0 & 0.0 \\
\hline \multirow{3}{*}{$\begin{array}{l}1396 \text { m Flow-Through } \\
\text { Experiment }\end{array}$} & Unreacted Reservoir & 77.1 & 25.8 & 0 & 0.0 & 0 & -1.7 \\
\hline & Midpoint Reservoir & 66.9 & 3.1 & 1.6 & 0.9 & 0 & 0.1 \\
\hline & Final Reservoir & 51.8 & 19.4 & 0 & 0.9 & 0 & 0.2 \\
\hline \multirow{3}{*}{ Control Test 2} & Unreacted Reservoir & 71.2 & 26.0 & 0 & 0 & 0 & -1.7 \\
\hline & Midpoint Reservoir & 85.2 & 20.7 & 0 & 0 & 0 & -0.3 \\
\hline & Final Reservoir & 45.3 & 19.0 & 0 & 0 & 0 & 0.2 \\
\hline
\end{tabular}

Table 5: Geochemical results from the high-temperature flow-through experiments and control tests 


\section{0 - References}

Ali, S.T., Davatzes, N.C., Feigl, K.L., Wang, H.F., Foxall, W., Mellors, R.J., Akerley, J., Zemach, E. and Spielman, P., 2015, Deformation at Brady Hot Springs Geothermal Field Measured by Time Seires Analysis of InSAR Data. Proceedings Fourtieth Workshop on Geothermal Reservoir Engineering: Stanford University, Stanford, California, p. 1-5.

Anderson, T. F., and Chai, B.H., 1979, Oxygen isotope exchange between calcite and water under hydrothermal conditions, Geochemical Transport and Kinetics, Carnegie Institution of Washington, p. 219-227.

Bächler, D., and Kohl, T., 2005, Coupled thermal-hydraulic-chemical modelling of enhanced geothermal systems, Geophysical Journal International, v. 161.2, p. 533-548.

Bromhal, G., Crandall, D., Eastman, H., Harbert, B., Haljasmaa, I., Siriwardane, H., Disenhof, C., Gill, M., Roberts, E., Gyovai, K., and Soong, Y., 2011, Rock core evaluation: Brady's Hot Springs well BCH-03, National Energy Technology Laboratory, p. 99-107.

Center for Climate Change and Energy Solutions, 2012, Enhanced geothermal systems, Center for Climate Change and Energy Solutions, p.1-9.

Chiba, H., and Sakai, H., 1985, Oxygen isotope exchange rate between dissolved sulfate and water at hydrothermal temperatures, Geochimica et Cosmochimica Acta, Elsevier Ltd., v. 49.4, p. 993-1000.

Clark, I.D., and Fritz, P., 1997, Environmental isotopes in hydrogeology, New York, CRC press, p.312

Cole, D.R., Ohmota, H., and Lasaga, A.C., 1983, Isotopic exchange in mineral-fluid systems. I. Theoretical evaluation of oxygen isotopic exchange accompanying surface reactions and diffusion, Geochimica et Cosmochimica Acta, Pergamon Press Ltd., v. 47.10, p. 1681-1693.

Cole, D.R., Mottl, M.J., and Ohmota, H., 1987, Isotopic exchange in mineral-fluid systems. II. Oxygen and hydrogen isotopic investigation of the experimental basalt-seawater system, Geochimica et Cosmochimica Acta, Pergamon Press Ltd., v. 51.6, p. 1523-1538.

Cole, D.R., 2000, Isotopic exchange in mineral-fluid systems. IV. The crystal chemical controls on oxygen isotope exchange rates in carbonate- $\mathrm{H} 2 \mathrm{O}$ and layer silicate- $\mathrm{H} 2 \mathrm{O}$ systems, Geochimica et Cosmochimica Acta, Pergamon Press Ltd., v. 64.5, p. 921-931.

Cole, D.R., and Chakraborty, S., 2001, Rates and mechanisms of isotopic exchange, Reviews in Mineralogy and Geochemistry, v. 43.1, p. 83-223.

Craig, H., 1963, The isotopic geochemistry of water and carbon in geothermal areas, Nuclear geology on geothermal areas, Spoleto, v. 1, p. 17-53.

Crandall, D., Wen, H., Li, L., and Hakala, A., 2014, Reactive geochemical flow modeling with CT scanned rock fractures, Proceedings 4th Joint US-European Fluids Engineering Division Summer Meeting collocated with the ASME 2014 12th International Conference on Nanochannels, Microchannels, and Minichannels: Chicago, IL, p. 1-8.

Ettinger, T., and Brugman, J., 1992, Brady Hot Springs geothermal power plant, Geothermal Resources Council Bulletin, v. 21.8, p. 259-264.

Faulds, J. E., Coolbaugh, M., Blewitt, G., and Henry, C.D., 2004, Why is Nevada in hot water? Structural controls and tectonic model of geothermal systems in the northwestern Great Basin, Geothermal Resources Council Transactions, v. 28, p. 649-654.

Faulds, J. E., Coolbaugh, M. F., Benoit, D., Oppliger, G., Perkins, M., Moeck, I., and Drakos, P., 2010, Structural controls of geothermal activity in the Northern Hot Springs Mountains, Western Nevada: The tale of three 
geothermal systems (Brady's, Desert Peak, and Desert Queen), Geothermal Resources Council Transactions, v. 34, p. 675-683.

Fridleifsson, I. B., Bertani, R., Huenges, E., Lund, J. W., Ragnarsson, A., and Rybach, L., 2008, The possible role and contribution of geothermal energy to the mitigation of climate change, IPCC scoping meeting on renewable energy sources, Luebeck, Germany, v. 20.25, p. 59-80.

Giggenbach, W. F., 1992, Isotopic shifts in waters from geothermal and volcanic systems along convergent plate boundaries and their origin, Earth and planetary science letters, v. 113.4, p. 495-510.

González-Partida, E., Viggiano-Guerra, J.C., and Pérez, R.J., 2008, Hydro-geochemical and isotopic fluid evolution of the Los Azufres caldera geothermal field, central Mexico, IOP Conference Series: Earth and Environmental Science, IOP Publishing, v. 3.1, p. 1-7.

Green, B.D., and Nix, R.G., 2006, Geothermal-The Energy under our Feet. National Renewable Energy Laboratory, p. 1-21.

Inguaggiato, S., Hidalgo, S., Beate, B., and Bourquin, J., 2010, Geochemical and isotopic characterization of volcanic and geothermal fluids discharged from the Ecuadorian volcanic arc, Geofluids, v. 10.4, p. 525541.

Kjartansdóttir, R., 2014, Carbon isotopes and systematics of Icelandic low-temperature geothermal waters, University of Iceland, p. 1-55.

Kratt, C., Calvin, W., and Coolbaugh, M., 2006, Geothermal exploration with Hymap hyperspectral data at Brady-Desert Peak, Nevada, Remote sensing of environment, v. 104.3, p. 313-324.

Kuo, G., 2012, Geothermal energy, World Future Review, v. 4.1, p. 5-7.

Stefansson, V., 2005, World geothermal assessment, Proceedings of the world geothermal congress, p. 24-29.

Ligang, Z., Jingxiu, L., Huanbo, Z., and Zhensheng, C., 1989, Oxygen isotope fractionation in the quartz-watersalt system, Economic Geology, v. 84.6, p. 1643-1650.

Lund, J.W., 1982, Direct use of geothermal resources, Proceedings of the Pacific Geothermal Conference and 4th New Zealand Geothermal Workshop, v. 2, p. 307-312.

Lutz, S.J., Hickman, S., Davatzes, N., Zemach, E., Drakos, P., and Robertson-Tait, A., 2010, Rock mechanical testing and petrologic analysis in support of well stimulation activities at the Desert Peak Geothermal Field, Nevada, Proceedings Thirty-Fifth Workshop on Geothermal Reservoir Engineering: Stanford University, Stanford, California, p. 1-11.

Matthews, A., Becknsale, R.D., and Durham, J.J., 1979, Oxygen isotope fractionation between rutile and water and geothermometry of metamorphic eclogites, Mineralogical Magazine, v. 43, p. 405-413.

Nevada Bureau of Mines and Geology, 2010, Brady's Hot Springs ONE Online Nevada Encyclopedia: http://www.onlinenevada.org/articles/bradys-hot-springs.

Panthi, S. R., 2003, Carbonate Chemistry and Calcium Carbonate Saturation State of Rural Water Supply Projects in Nepal, Proceedings Seventh International Water Technology Conference: Aswan city, Egypt, p. 545560 .

Palandri, J.L., and Kharaka, Y.K., 2004, A compilation of rate parameters of water-mineral interaction kinetics for application to geochemical modeling, OPEN FILE REPORT 2004-1068: United States Geological Survey Menlo Park, CA, p. 1-71.

Phillips, F.M., Bentley, H.W., Davis, S.N., Elmore, D., and Swanick, G.B., 1986, Chlorine 36 dating of very old groundwater: 2. Milk River aquifer, Alberta, Canada, Water Resources Research, v. 22.13, p. 2003-2016.

Pistone, S., Stacey, R. and Horne, R., 2011, The significance of $\mathrm{CO}_{2}$ solubility in geothermal reservoirs. Proceedings Thirty-Sixth Workshop on Geothermal Reservoir Engineering: Stanford University, Stanford, California, p. 1-6. 
Polsky, Y., Capuano Jr, L., Finger, J., Huh, M., Knudsen, S., Chip, A.J., and Swanson, R. 2008, Enhanced geothermal systems (EGS) well construction technology evaluation report, SAND2008-7866: Sandia National Laboratories, p. 1-108.

Qin, D., Turner, J. V., and Pang, Z., 2005, Hydrogeochemistry and groundwater circulation in the Xi'an geothermal field, China, Geothermics, v. 34.4, p. 471-494.

Sanliyuksel, D., and Baba, A., 2011, Hydrogeochemical and isotopic composition of a low-temperature geothermal source in northwest Turkey: case study of Kirkgecit geothermal area, Environmental Earth Sciences, v. 62.3, p. 529-540.

Sanyal, S.K., and Butler, S.J., 2005, An analysis of power generation prospects from enhanced geothermal systems, Geothermal Resources Council Transactions, v. 29, p. 1-6.

Schulte, P., Van Geldern, R., Freitag, H., Karim, A., Négrel, P., Petelet-Giraud, E., and Barth, J.A., 2011, Applications of stable water and carbon isotopes in watershed research: Weathering, carbon cycling, and water balances, Earth-Science Reviews, v. 109.1, p. 20-31.

Sharp, Z., 2007, Principles of stable isotope geochemistry: Upper Saddle River, NJ, Pearson education, p. 1-334.

Simsek, S., 2003, Hydrogeological and isotopic survey of geothermal fields in the Buyuk Menderes graben, Turkey, Geothermics, v. 32.4, p. 669-678.

Smith, M.M. and Carroll, S.A., 2014, February. Experimental determination of chlorite kinetics at geothermal conditions, Proceedings 39th Workshop on Geothermal Reservoir Engineering: Stanford University, Stanford, California, p. 1-9.

Stumm, W., and Morgan, J.J., 1996, Aquatic chemistry: Chemical equilibria and rates in natural waters, New York, John Wiley \& Sons, v. 3, p. 1022.

Taron, J., and Elsworth, D., 2010, Coupled mechanical and chemical processes in engineered geothermal reservoirs with dynamic permeability, International Journal of Rock Mechanics and Mining Sciences, v. 47.8, p. 1339-1348.

Tester, J.W., Anderson, B.J, Batchelor, A.S, Blackwell, D.D, DiPippo, R., Drake, E.M., and Richards, M., 2006, The future of geothermal energy, Massachusetts Institute of Technology, v. 358, p. 1-23.

Tester, J.W., Anderson, B.J., Batchelor, A.S., Blackwell, D.D., DiPippo, R., Drake, E.M., and Richards, M., 2007, Impact of enhanced geothermal systems on US energy supply in the twenty-first century Philosophical Transactions of the Royal Society A: Mathematical, Physical and Engineering Sciences, v, 365.1853, p. 1057-1094.

Truesdell, A.H., Nathenson, M., and Rye, R.O., 1977, The effects of subsurface boiling and dilution on the isotopic compositions of Yellowstone thermal waters, Journal of Geophysical Research, v. 82.26, p. 3694-3704.

Wojtowicz, J.A., 2001, Calcium carbonate precipitation potential, Journal of the Swimming Pool and Spa Industry, v. 2.2, p. 23-29.

Xu, T., Ontoy, Y., Molling, P., Spycher, N., Parini, M., and Pruess, K., 2004, Reactive transport modeling of injection well scaling and acidizing at Tiwi field, Philippines, Geothermics, v. 33.4, p. 477-491.

Zheng, Y. F., 1999, Oxygen isotope fractionation in carbonate and sulfate minerals, Geochemical Journal-Japan, v. 33, p. 109-126. 